Quel AVENIR POUR LE DESSIN DE PRESSE?

할 크 है है 11 


\section{Quel avenir pour le dessin de presse?}

DOI : 10.4000/books.bibpompidou. 1252

Éditeur : Éditions de la Bibliothèque publique d'information

Année d'édition : 2009

Date de mise en ligne : 17 janvier 2014

Collection : Paroles en réseau

ISBN électronique : 9782842462000

\section{Qbooks}

http://books.openedition.org

\section{Édition imprimée}

ISBN : 9782842461249

Nombre de pages : 66

\section{Référence électronique}

- Quel avenir pour le dessin de presse ? Nouvelle édition [en ligne]. Paris : Éditions de la Bibliothèque publique d'information, 2009 (généré le 02 février 2021). Disponible sur Internet : <http://

books.openedition.org/bibpompidou/1252>. ISBN : 9782842462000. DOI : https://doi.org/10.4000/ books.bibpompidou.1252

(c) Éditions de la Bibliothèque publique d'information, 2009

Conditions d'utilisation :

http://www.openedition.org/6540 


\section{Quel avenir pour le dessin de presse?}

Actes du colloque organisé par la Bpi

le vendredi 26 septembre 2008 ,

dans la Petite Salle du Centre Pompidou

Bibliothèque

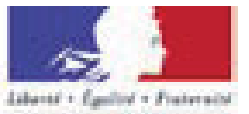

Rircaugue Funçuse:

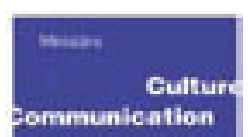




\section{Président du Centre Pompidou \\ Alain Seban \\ Directrice générale du Centre Pompidou Agnès Saal \\ Directeur de la Bpi Thierry Grognet}

Responsable du pôle Action culturelle et communication Philippe Charrier

\section{Chef du service} Animations

Emmanuelle Payen

\section{Chef du service} Édition/Diffusion Arielle Rousselle
Débat Conception et organisation Isabelle Bastian-Dupleix

\section{Publication}

\section{Chargées d'édition}

Geneviève Kindt

Mélanie Daubié

\section{Mise en page}

Mélanie Daubié

\footnotetext{
Catalogue disponible sur http://www.bpi.fr, rubrique Éditions de la Bibliothèque publique d'information Distribution numérique par GiantChair.com

(C) Éditions de la Bibliothèque publique d'information/Centre Pompidou, 2009.

ISBN 978-2-84246-124-9 ISSN 1765-2782
} 


\section{Sommaire}

\section{Vendredi 26 septembre 2008}

\section{$4 \quad$ Introduction}

Thierry Grognet et François Forcadell

5 Conférence : L'histoire du dessin de presse Guillaume Doizy

\section{Entretien}

Charb et François Forcadell

42 Table ronde : Quel avenir pour le dessin de presse ? Modérateur : François Forcadell

Alain Blaise, Charb, Odile Conseil, Bernard Fournier et Luce Mondor 


\section{Introduction}

\section{Thierry Grognet* et François Forcadell*}

Thierry Grognet : Bienvenue au Centre Pompidou, sous l'égide de la Bibliothèque publique d'information, pour cette journée consacrée à l'avenir du dessin de presse. Comme vous le savez, une exposition qui se clôture lundi a présenté durant tout l'été l'univers graphique de Łean Gourmelin - après l'œuvre de Willem et celle de Reiser.

C'est donc un axe important pour la bibliothèque que de présenter la création contemporaine dans le domaine du dessin, et plus spécifiquement $\mathrm{du}$ dessin de presse. C'est aussi un axe important pour nous que de faire toute la place à l'actualité et à la prospective, d'où l'organisation de cette journée d'étude sous l'égide de François Forcadell ${ }^{1}$, qui assurait - en tant que conseiller scientifique - l'accompagnement de nos collègues de la bibliothèque, Emmanuelle Payen et Florence Verdeille, pour l'organisation à la fois de l'exposition et de cette session qui nous rassemble aujourd'hui.

Sans plus tarder, je laisse la parole à François Forcadell pour une présentation plus précise de ces débats. Merci.

François Forcadell : Bonjour. Je vous remercie, tout d'abord, d'être venus aujourd'hui. Cette manifestation clôture donc l'exposition Gourmelin, qui est encore visible jusqu'au 30 septembre. Si vous ne l'avez pas vue, vous avez encore quelques jours pour y jeter un coup d'œil.

Le programme de cette journée débutera par une intervention de Guillaume Doizy : il va faire un historique de la caricature à travers les âges, mais je vous rassure, c'est un condensé. Ensuite, j'aurai un entretien avec Charb, qui est ici : c'est le dessinateur et rédacteur en chef adjoint de Charlie Hebdo. L'entretien durera à peu près trois quarts d'heure. On passera en revue sa carrière, son parcours de dessinateur et, à la fin de l'entretien, vous pourrez lui poser des questions.

Puis nous aurons un forum-débat avec des spécialistes du dessin de presse : Alain Blaise, directeur artistique à Libération, Bernard Founier, directeur artistique également, qui fait aussi des livres, Odile Conseil qui travaille au Courrier International et s'occupe d'une agence de dessin au sein de son journal, et enfin Luce Mondor ${ }^{2}$, qui est professeur de lettres à l'École Estienne et s'occupe du prix Presse Citron chaque année. C'est un prix qui est fait pour moitié par les professionnels et pour moitié par des élèves de toutes les écoles d'art de France.

Je passe la parole à Guillaume Doizy, auteur de livres sur la caricature : il maîtrise parfaitement le sujet. 


\section{L'histoire du dessin de presse}

\section{Guillaume Doizy*}

Pour tout vous dire, je me demande encore si j'ai eu raison d'accepter de venir raconter ici l'histoire du dessin de presse ! Évoquer l'œuvre de Daumier en trois quarts d'heure serait déjà une gageure. Parler de L'Assiette au Beurre en un temps si court, analyser plusieurs milliers de ses dessins et le travail de dizaines d'artistes ayant collaboré à la revue relèverait du miracle. On pourrait écrire aussi des livres entiers sur le dessin de presse des Années folles. Je ne dois pas seulement parler d'un dessinateur, d'un journal ou encore d'une période, je dois en outre vous raconter deux siècles d'une production immense qui se chiffre en centaines de milliers, voire en millions d'images et vous décrire l'existence et l'évolution d'une pléthore d'organes de presse. Je dois mettre en lumière le travail de milliers de caricaturistes, sans parler du lectorat, des autres supports sur lesquels on trouve l'image satirique - et encore, en se limitant à la France et en faisant l'impasse sur les périodes qui précèdent la naissance de la presse moderne. Alors, bien sûr, il me faudra parcourir cette histoire à grands pas, en fermant les yeux sur les nombreuses richesses qu'elle recèle : un exercice périlleux. Pour commencer, il me semble nécessaire de faire un peu de linguistique.

L'expression "dessin de presse " apparait, semble-t-il, pour la première fois en 1979, dans le titre d'un colloque organisé à Grenoble sur Daumier. Elle devient à la mode à partir des années 1990. Jusqu'alors, pour qualifier les images dont je vais faire l'historique, on employait - et on emploie encore - les termes de :

- caricatures ;

- dessins d'humour, gais ou drôles ;

- dessins de mœurs ;

- charges ;

- portraits-charges ;

- gravures comiques ;

- dessins satiriques ou politiques ;

- satires ;

- humour graphique.

Certains de ces termes renvoient, selon les auteurs, à des réalités très différentes et ont parfois chez d'autres valeur de synonymes. Le sens de ces mots évolue au fil du temps, certaines expressions apparaissent tandis que d'autres tombent dans l'oubli. Dans leur ouvrage L'Art et l'histoire de la caricature ${ }^{3}$, Martial Guedron et Laurent Baridon rappellent que la caricature, je cite : "se dérobe à tout principe, à toute définition ", tant il est vrai que ce genre englobe une réalité plurielle et mouvante en permanente évolution. On peut parler de caricatures aussi bien pour désigner un graffiti antireligieux des premiers temps de l'ère chrétienne qu'une marionnette des Guignols de l'Info. Pourtant, quel chemin parcouru entre les deux ! Le terme " caricature » est souvent employé de manière générique et vaut pour qualifier une gamme assez vaste d'images satiriques. Dans certains cas, " caricature " renvoie à l'art de révéler une personnalité par la déformation des traits du visage, art qui naît en Italie avec les frères Carrache ${ }^{4}$.

Autre terme générique, l'image satirique. Mais la satire porte en elle une part de critique sociale et donc exclut le dessin comique ou d'humour, c'est-à-dire l'ensemble des images propres à faire rire, en général sans 
grande portée politique ou sociale. Avec l'humour graphique - encore une expression - nous évoquons une tendance très originale du dessin d'humour, plus raffinée, qui s'épanouit après la Seconde Guerre mondiale. Quant à l'expression "dessin de presse ", elle évoque d'abord, bien sûr, le support sur lequel seront diffusées ces images, c'est-à-dire le journal. Mais, de manière plus précise, l'expression caractérise un genre : le dessin d'actualité ou dessin politique.

Comme on le voit, il est bien difficile de s'accorder sur une définition, de trouver le mot qui permette de décrire l'ensemble de ces images, sans en exclure aucune. Le problème réside surtout dans le fait que la presse accueille une gamme très large de dessins satiriques aux fonctions très variées, ces dessins héritant eux-mêmes de traditions très anciennes, bien antérieures à la naissance de la presse moderne. L'inconvénient avec l'expression "dessin de presse ", qui est donc utilisée dans la plaquette de la BDIC $^{5}$, c'est qu'elle ne rend pas compte de la grande variété des supports qu'empruntent les images satiriques, comme on le verra. On comprend donc pourquoi, encore aujourd'hui, aucune expression ne parvient à faire l'unanimité.

François Forcadell a employé le mot "caricature " et a dit que je ferai l'historique de la caricature, alors que le titre annonce le dessin de presse. En fait, nous emploierons " caricature ", "dessin de presse " et "image satirique » souvent de manière générique et comme synonymes, mais parfois nous insisterons sur les nuances que chacune de ces expressions permet d'évoquer. Pour comprendre de quoi il retourne, il me semble nécessaire de s'interroger sur les différentes fonctions de l'image satirique. On peut, à mon sens, distinguer trois fonctions principales :

- la propagande ;

- le commentaire ;

- le divertissement par le rire.

La propagande d'abord: pendant les crises politiques et sociales intenses - voire dans les périodes plus calmes - le dessin de presse se fait parfois polémiste et propagandiste, marchant sur les pas de Luther et de son acolyte Lucas Cranach ${ }^{6}$, du temps de la Réforme. Il défend un camp avec outrance, accable ses adversaires et parfois se retrouve dans des organes politiques et militants fondés par des partis qui voient dans la caricature un excellent moyen de diffuser des idées : il s'agit de susciter l'indignation du lecteur et de le pousser à son tour à s'engager. Le dessin propagandiste vise en général à dégager des types, à mettre en scène des idées générales. Ces images souvent violentes répètent des stéréotypes outranciers, sans chercher particulièrement à répondre à l'actualité, en mettant en avant quelques axes considérés comme majeurs. Du point de vue du support, le dessin de propagande recourra volontiers aux feuilles volantes, à l'affiche, aux vignettes et, depuis quelques décennies, à la carte postale ou aux autocollants, tous supports relativement faciles à produire, s'adressant au plus grand nombre et susceptibles d'être facilement diffusés par un milieu militant. On trouve de tels dessins, évidemment, dans les journaux engagés.

Quelle influence ces images peuvent-elles avoir sur les consciences? Il est bien difficile de le dire. Si la caricature ne semble pas pouvoir vraiment

Conférence: L'histoire du dessin de presse par Guillaume Doizy 
inverser une opinion, on peut tout de même imaginer qu'elle renforce les convictions. Le dessin engagé cimente une communauté de points de vue et accentue les clivages. Mais la caricature pousse-t-elle à l'action ? On prend souvent l'affaire Dreyfus en exemple pour montrer l'influence de la caricature sur les opinions. Des centaines d'images formulaient à l'époque de véritables appels au meurtre contre les Juifs, par exemple dans L'Antijuif illustré . Pour autant, il n'est à déplorer aucun mort dans la communauté juive en métropole à l'époque. Tandis que dans les années 1880, c'està-dire un peu plus d'une dizaine d'années auparavant, alors qu'aucune caricature ne vise particulièrement les Italiens, de nombreuses agressions sont commises contre eux sur le sol français, avec des morts à la clé.

La caricature en tant qu'instrument de propagande ne fait pas l'unanimité, comme l'indique une enquête menée en 1906 par l'historien de l'image satirique John Grand-Carteret ${ }^{8}$. L'auteur interroge les élites de la gauche radicale pour savoir si elles considèrent la caricature comme un bon moyen de faire de la propagande pour la séparation de l'Église et de l'État. Les intellectuels et les édiles politiques de haut rang se déclarent réticents envers ce genre qu'ils considèrent comme outrancier, alors que les journalistes et les militants se disent, au contraire, enthousiastes par rapport à ces images qui permettent de toucher les esprits avec force et réussissent à faire enrager l'adversaire.

Autre rôle du dessin de presse, autre niveau d'engagement : il commente. Plutôt que le registre propagandiste, le dessinateur peut choisir la position de l'observateur ironique qui raille, autant dans le but de souligner une contradiction que d'amuser son lecteur. Cette attitude peut, dans certains cas, être induite par la censure qui empêche un engagement trop évident. Le dessin met en scène les péripéties du pouvoir et les travers de la société. Il cherche à édifier les lecteurs en exprimant une opinion plus ou moins tranchée. Le ton se montre moins violent que pour la propagande et les thèmes abordés collent à l'actualité politique et sociale. C'est l'état d'esprit de très nombreux dessins parus dans la presse depuis deux siècles et, notamment, ces dernières décennies. C'est ce type de dessin qui nous est aujourd'hui le plus familier.

Troisième fonction, le dessin de presse amuse. Amuser peut, en effet, devenir l'ultime objectif du dessin paru dans un journal : amuser grâce à un bon mot, un calembour littéraire ou visuel, ou une légende légère sur un dessin qui met en scène des situations stéréotypées, tirées de la vie quotidienne. Le dessin de presse amuse parfois malgré la contrainte, comme après 1835 ou 1851, lorsque les lois sur la presse se font plus dures. Quand la censure interdit de traiter les sujets politiques, le dessinateur se contente d'égayer son lecteur avec les travers de la vie artistique - par exemple en caricaturant les salons - ceux de la vie quotidienne, et également les travers sociaux ou professionnels, sans exprimer une véritable opinion sur ces sujets. Une partie du dessin amusant se distingue également par sa propension à déshabiller les femmes. C'est la gaudriole, thématique très répandue. Le genre du dessin amusant se perpétue au $\mathrm{Xx}^{\mathrm{e}}$ siècle comme digne représentant de l'increvable Almanach Vermot ou encore du Hérisson.

Mais dans les années 1950, sous l'influence de dessinateurs américains comme Saul Steinberg, James Thurber et Peter Arno, apparaît un genre tota- 
lement inédit - ce qu'il est convenu d'appeler l'humour graphique - qui se passe souvent de légende, fascine par sa simplicité et par l'incongruité des situations mises en scène. Il joue sur l'absurde, le non-sens et l'humour noir, se nourrit des expériences du surréalisme, comme chez Maurice Henry, Chaval, Mose, Bosc, André François et, évidemment, Gourmelin, dont la Bpi expose les œuvres. Le journal Paris Match, après la Seconde Guerre mondiale, joue un rôle primordial dans la diffusion de ce type de dessins en France. Alors, évidemment, le dessin satirique n'est pas sécable en trois compartiments homogènes et imperméables. Comme toute typologie, celle-ci a un caractère forcément réducteur, mais elle permet de s'interroger sur la diversité des fonctions de ces dessins et donc sur les différences de supports, de conditions de diffusion et de réception, qui varient également.

Intéressons-nous maintenant à la rhétorique de ces images. La caricature déforme, exagère les traits, fonctionne comme une loupe suggestive qui choisirait de mettre l'accent sur un détail ou, au contraire, de minimiser tel autre aspect. Elle focalise le regard sur les traits du visage ou les caractéristiques corporelles, s'appuyant sur une croyance largement répandue qui voit dans les traits physiques le reflet des tréfonds de l'âme. Au XIx ${ }^{e}$ siècle, la caricature trouve dans la physiognomonie de Lavater et la phrénologie de Gall une base qui se veut scientifique. Le dessin de presse politique utilise bien sûr ces procédés de déformation, mais imagine également des situations, met en scène une action, un problème, une crise, joue avec les métaphores et les attributs. Les deux genres cohabitent et se nourrissent tous deux des facéties du verbe. L'image satirique emprunte en effet à la rhétorique du discours et, notamment, du discours polémique. On peut se référer à l'immense production graphique et pamphlétaire de la Révolution française. Pour le $\mathrm{XIX}^{\mathrm{e}}$ siècle, il n'est pas difficile de trouver d innombrables correspondances entre la satire, le discours politique et la caricature. La charge puise dans le langage imagé et emphatique où prédominent l'outrance verbale et la métaphore. Si la caricature joue sur les déformations, le dessin satirique opère sur un terrain plus complexe et combine des éléments disparates - protagonistes, situations, symboles - qui, par le fait de la contamination et de la condensation, feront sens. La satire en image se nourrit de références littéraires, historiques et religieuses. Elle s'adresse alors à un public cultivé.

Dans les images, on peut voir par exemple des références à la sculpture ou à la mythologie, des références littéraires, comme à La Fontaine avec "Le Pélerin " ou des métaphores religieuses, comme pour Léon Blum, évidemment. Il y a aussi l'allégorie, qui n'est pas obligatoirement féminine et passe de mode au xxe siècle. Bien sûr, on pense aussi à l'animalisation, particulièrement efficace au XIX ${ }^{\mathrm{e}}$ siècle où l'on se passionne pour les sciences naturelles et l'univers du bas corporel.

La rhétorique caricaturale s'appuie également sur l'anachronisme, l'infantilisation, la féminisation péjorative, le carnavalesque, etc. En cela, le dessin de presse hérite de traditions anciennes. En fait, le langage de ces images oscille entre tradition et innovation. Le dessinateur utilise des codes qui doivent être compris par le lecteur. Il puise ses stéréotypes dans la culture commune mais commente une réalité en permanente 
évolution et s'en nourrit. La caricature fonctionne comme une éponge. Elle intègre comme procédé tout objet ou événement qui rencontre un écho dans la société et crée à son tour de nouveaux stéréotypes. Ainsi, les études sur la folie dans les années 1820 invitent Daumier à présenter les "Célébrités du Juste Milieu " sous l'apparence de malades mentaux. De même, quand le chemin de fer se développe, la caricature la plus frileuse dénonce un moyen de transport " dangereux ", tandis que les dessinateurs progressistes emploient la métaphore ferroviaire pour symboliser les progrès des idées républicaines. Mais le dessinateur doit également faire preuve d'inventivité pour se distinguer de ses confrères et séduire un public avide de se laisser surprendre. Restent les limites d'un langage qui ne serait pas assez partagé et qui peut entraîner l'incompréhension. Il faut, bien sûr, une communauté de points de vue entre le dessinateur et son lecteur. Un dessin de Charlie Hebdo publié dans Le Figaro aurait peu de chance de faire rire mais susciterait plutôt le rejet. On a, dans le passé, des exemples d'images totalement contre-productives qui servent leurs cibles plutôt que de parvenir à leur nuire.

Après ce petit tour d'horizon analytique, intéressons-nous à l'évolution du dessin de presse depuis deux siècles. Le dessin de presse au sens strict, celui que nous connaissons encore aujourd'hui, naît en 1830 en France. Si la France se montre alors originale et invente un genre qui va connaître un succès international, il faut se rappeler que la caricature, dans les décennies et les siècles qui ont précédé, a plutôt brillé ailleurs, en Allemagne, en Italie, dans les Flandres et, au XVIII ${ }^{e}$ siècle, en Angleterre. Pourquoi cette originalité française en 1830 ? Deux phénomènes majeurs se combinent :

- la révolution politique et sociale, qui entraîne un bouillonnement dans le domaine des idées et une grande liberté d'expression ;

- les progrès en matière d'impression des journaux, et surtout d'impression des images, notamment avec une technique nouvelle, la lithographie.

C'est cette technique-là que le dessinateur Philippon associe de manière systématique à la presse en publiant à partir de 1830 un organe d'un genre nouveau, le journal satirique illustré. Il publie d'abord un hebdomadaire, $\underline{L a}$ Caricature puis, en 1832, un quotidien, Le Charivari que l'on trouve encore dans les kiosques en 1900. Tous deux mêlent texte et image et vont inspirer de nombreux organes similaires en Europe :

- en Angleterre paraît Punch en 1841, sous-titré d'ailleurs London Charivari;

- l'Allemagne s'illustre avec le Fliegende Blätter en 1845, ainsi qu'avec le Berliner Charivari et le Kladderadatsch;

- en Italie, on peut lire Il Fischietto à partir de 1848.

Philippon, en fondant la maison Aubert, s'entoure des meilleurs dessinateurs du moment. Il diffuse autant des dessins virulents visant le personnel politique représenté par exemple dans le "Juste Milieu » que des charges plus amusantes, moins corrosives, qui intéressent les lecteurs aux fantaisies de l'époque. Il ne faut pas croire que le journal La Caricature bénéficie alors d'une large audience. L'abonnement annuel équivaut à un mois de salaire ouvrier et l'hebdomadaire compte entre deux mille et trois mille abonnés seulement. De plus, Philippon fait des émules chez ses adversaires, comme

Conférence: L'histoire du dessin de presse par Guillaume Doizy 
La Charge $^{10}$ qui paraît en 1832 et défend Louis-Philippe.

Le dessin reste pétri de références littéraires et artistiques. Dans La Caricature et Le Charivari, les cibles, hommes politiques ou journalistes en vue, très reconnaissables, s'agitent sur une scène de théâtre dont le décor est complexe. Le dessin cherche à faire illusion, travaille les expressions, les postures, les costumes, multiplie les attributs. La lithographie joue du modelé comme dans la peinture, puise dans l'art classique du dessin un savoir-faire propre à satisfaire l'œil. Les dessinateurs inventent de nouvelles figures qui rencontrent un franc succès dans le public. « La Métamorphose du roi Louis-Philippe en poire " de Philippon devient un instrument de dénigrement systématique contre Louis-Philippe. Traviès crée le personnage de Mayeux puis Daumier invente plus tard celui de Ratapoil. Grandville se spécialise dans la satire animalière et rencontre un immense succès avec ses Métamorphoses du Jour. Le journal satirique crée alors un imaginaire qui modèle celui de son lecteur au fil des semaines, voire au fil des jours. Mais les conditions de liberté permises par les Trois Glorieuses ne durent pas. Les journaux subissent les coups de la censure, tout comme après 1851. Quand la liberté fait défaut, le dessin politique rentre en sommeil. Pour autant, le public demeure avide d'images. Les journaux amusants se multiplient. On édite des séries de vignettes drolatiques dans des périodiques et des albums à succès, notamment ceux de Cham ${ }^{11}$, un des plus prolifiques en la matière. Si la politique intérieure ne peut faire l'objet de railleries, on s'intéresse aux tensions internationales. On peut dire que dans les années 1850 le dessin de presse, dans sa version comique, touche enfin toutes les couches de la société. Après 1850, on se passionne pour les célébrités du temps. Les biographies satiriques et leurs versions imagées se multiplient, ainsi que les divers panthéons ou trombinoscopes qui les accompagnent. C'est l'âge d'or du portrait-charge.

La production du dessin de presse suit évidemment les aléas des crises politiques. Avec la chute de Napoléon III, les journaux à caricatures laissent place à un fourmillement de feuilles volantes. Le dessin trouve à se diffuser sur des supports plus faciles à produire, faciles à afficher, circulant de main en main. Ces innombrables feuilles montrent l'importance acquise par l'image dans la matérialisation des aspirations, des peurs et des haines humaines. Quand les tensions sont à leur apogée, l'homme semble soudain avide de représentations les plus extrêmes. La retenue et les tabous disparaissent. Le dessin devient alors violemment scatologique, trivial, scabreux ou ordurier, s'inscrivant pour partie dans une tradition pornographique fort ancienne que l'on retrouve déjà au moment de la Révolution française. Ce langage révèle la violence des clivages politiques et sociaux d'alors, violence qui s'exprime non seulement dans les nombreux clubs qui se fondent mais aussi dans les journaux qui défendent chaque camp. Le dessin de presse, le journal satirique, reflètent partiellement l'état des forces sociales et des opinions. Après la répression de la Commune, les plumes et les pinceaux sont sévèrement encadrés mais les journaux satiriques, hebdomadaires surtout, se multiplient quand même, composant avec la censure et la dénonçant souvent. On imprime toujours plus facilement et à moindre coût, l'illustration envahit l'imprimé et, finalement, tous les camps politiques d'une certaine importance s'intéressent à la caricature. Chacun ou

Conférence : L'histoire du dessin de presse par Guillaume Doizy 
presque fonde son journal, d'autant plus aisément avec la loi républicaine de 1881 qui libéralise la presse, mettant fin au contrôle administratif et à l'obligation de demander une autorisation à la personne dont on souhaite publier la charge. La loi autorise presque toutes les outrances, sauf à s'attaquer aux chefs d'États étrangers, à l'armée et à se montrer trop osé sur le terrain des mours.

Après 1881, la censure disparaît presque totalement mais les pressions économiques prennent parfois le relais. Elles sont évidemment difficiles à évaluer. Le camp républicain compte alors de nombreux titres, petits ou grands, plus ou moins durables, avec par exemple André Gill ${ }^{12}$ et Alfred Le Petit ${ }^{13}$. De l'autre côté, les bonapartistes, les monarchistes, les antisémites et les cléricaux ne font pas défaut. À partir des années 1880, les journaux quotidiens sérieux commencent, eux aussi, à publier des dessins politiques et d'actualité, souvent un par semaine, parfois un par jour. Le dessin, qui prend là des galons, se simplifie. Il se limite au noir et blanc, le plus souvent apparait au trait, en général de petite taille, mais parfois s'étale sur toute la page. On trouve de tels dessins au Figaro comme à gauche, à La Nation, à L'Écho de France, à La Croix et dans bien d'autres quotidiens, puis plus tard à L'Humanité, qui en 1908 publie des dessins de Gassier notamment, voire plus exceptionnellement de Steinlen ${ }^{14}$ - malheureusement, ces dessins perdent parfois en qualité quand ils sont reproduits par procédé photomécanique, sans parler de certains papiers d'imprimerie à l'époque, qui laissaient apparaître par transparence le texte au verso. Certains journaux mettent en avant le fait de publier tel ou tel artiste, comme Forain qui a la cote. La renommée du dessinateur, de même qu'aujourd'hui, joue déjà fortement. Les autoportraits des dessinateurs commencent à se multiplier mais la célébrité de quelques-uns ne doit pas masquer la précarité de centaines d'autres. Le dessinateur a rarement l'assurance de voir ses dessins publiés et les relations d'un artiste habitué d'un journal peuvent se tendre jusqu'à la rupture.

Cet âge d'or du dessin de presse s'illustre également en province. À Rouen par exemple, avant 1870 , se publient deux hebdomadaires satiriques, $L e$ Tambour et Le Tam Tam ${ }^{15}$. À Lyon, on peut lire La Comédie politique. En 1874, à Bordeaux, Gilbert-Martin fonde Le Don Quichotte, qui obtient un succès national. Après 1881, ce sont des centaines d'illustrés régionaux ou locaux qui se publient. Ils offrent aux lecteurs des villes moyennes, voire aux ruraux, une vision caricaturale de la vie locale ou des images de portée plus générale. On trouve à Marseille La Calotte, à Reims L'Etrille. De 1885 à 1911, La Cloche Illustrée se publie au Havre. On voit que ces noms de journaux, même en province, perdurent. À Rouen, le dessinateur Pépin travaille pour Le Petit Ronennais (voir en bas de page « Jacques Bonhomme et les impôts "). À titre anecdotique, dans la ville de Chauny ${ }^{16}$, dans l'Aisne, un journal conservateur trihebdomadaire publie en 1902 et 1903 une grande caricature politique chaque semaine, parfois reproduite sous forme de chanson ou d'album illustré. Pourtant, la ville ne comprend que 10000 habitants! Chaque ville moyenne, chaque région, possède en 1900 son ou ses journaux satiriques illustrés. On voit là le succès du dessin de presse à la Belle Époque. On trouve évidemment aussi de tels journaux dans les colonies. 
Il est impossible de restituer ici toute la diversité du dessin de presse à la fin du XIX $x^{e}$ siècle. Évoquons tout de même des journaux qui se créent et disparaissent le temps d'une crise politique, comme pendant l'affaire Boulanger et l'affaire Dreyfus. Évoquons également des revues de tendance plus littéraire et reflétant l'esprit de Montmartre, comme Le Courrier Français avec Willette, ou plus humoristiques comme Le Rire ${ }^{17}$ et Le Sourire et, encore plus osée, Le Frou-Frou. Le Rire, fondé en 1894, publie entre autres des dessins puisés dans la presse européenne, permettant aux stéréotypes de circuler et de s'uniformiser au-delà des frontières. C'est une des caractéristiques du moment. L'hebdomadaire devance en cela Courrier International en reproduisant des vignettes de la presse allemande, anglaise, américaine, russe, etc. Les images circulent, les dessinateurs aussi, certains pour échapper à la répression, d'autres pour trouver du travail. En 1900, des dizaines de dessinateurs étrangers participent, par exemple, à L'Assiette au Beurre.

À la fin du XIX siècle, on trouve des hebdomadaires de grand format, illustrés d'une seule grande caricature en noir ou en couleur, souvent fondés par le dessinateur lui-même. Le lecteur peut également choisir parmi des revues de taille plus modeste mais au nombre de pages supérieur, parfois sans texte et accueillant des dizaines de dessins. Certains hebdomadaires satiriques mènent, quand ils en ont les moyens, de véritables expériences esthétiques. On peut évoquer L'Assiette au Beurre mais aussi Le Cocorico, moins connu, dont le dessin de titre se renouvelle chaque semaine. La mise en page change brutalement. Les vignettes rectangulaires ou carrées, insérées dans des colonnes de texte régulières, sont abandonnées pour une véritable intégration texte-image. La division par pages laisse parfois place à une composition par double page dans laquelle circule le regard. Les jeux graphiques se multiplient et le point d'interrogation, par exemple, rentre de plus en plus dans la caricature. Ces expérimentations puisent dans les trouvailles des avant-gardes artistiques. On pense aux Arts incohérents par exemple, et aussi à l'Art nouveau. Lautrec, $\underline{\mathrm{Gris}}^{18}, \underline{\mathrm{Kupka}}^{19}, \underline{\mathrm{Luce}}^{20}$ et bien d'autres sont autant des dessinateurs satiriques que des peintres novateurs. La photographie influence, elle aussi, la caricature par ses cadrages extrêmes. Elle permet les premiers photomontages et des mises en scène satiriques qui ne sont plus dessinées.

Le support se diversifie. La caricature se publie sur des cartes postales, des cartes à jouer, des jeux de l'oie, des assiettes, des affiches, des enveloppes et, depuis longtemps, on regrave des monnaies. Des sculptures en plâtre ou en pain d'épice s'attaquent aux hommes célèbres. On édite des verres à bière comiques. On sculpte des marrons ou on modèle des peaux d'orange. Le lecteur a alors l'embarras du choix. Les kiosques fourmillent de titres satiriques divers, sur tous les sujets possibles, pour tous les styles, pour tous les âges. Puis, après 1900, apparaît une imagerie à caractère social. À partir de la parution du Chambard Socialiste, les dessinateurs s'engagent auprès des anarchistes et des syndicalistes. Des stéréotypes nouveaux apparaissent :

- l'officier, en général cruel et inhumain ;

- le magistrat qui défend les puissants plutôt que le malheureux ;

- le curé, enrichi et pédophile ; 
- et surtout le bourgeois exploiteur.

Toute une rhétorique du gros se met en place par opposition au petit, à l'exploité. Le gros bourgeois, surtout, dont la panse démesurée devient un coffre-fort. L'ouvrier apparait jeune et musclé, les foules manifestent leur colère. Les anarchistes et les syndicalistes publient des journaux illustrés de dessins satiriques, notamment Les Temps nouveaux, La Guerre sociale, La Voix du peuple, Le Terrassier et La Bataille syndicaliste. À cette époque naît l'affiche politique illustrée avec, par exemple, Grandjouan. Après 1910, l'ambiance change. Certaines revues-phares de la période s'éteignent et on peut relever, ici où là, la montée du nationalisme.

Pendant la Première Guerre mondiale, le dessin de presse défend l'Union sacrée. Comme un seul homme ou presque, les dessinateurs les plus hostiles à la guerre avant 1914 se mettent au diapason. Le Rire, qui devient alors Le Rire Rouge, tient à justifier la poursuite de sa parution malgré les heures graves qui s'annoncent, en expliquant qu'il s'agit là d'un choix patriotique. Il s'engage à dénoncer l'ennemi et à galvaniser les troupes. Évoquons également La Baïonnette parmi une pléthore de titres qui présentent l'ennemi comme un monstre hybride, sanguinaire et piètre soldat. On s'intéresse également à la vie des tranchées ou de l'arrière. Ces deux thèmes sont traités parfois avec légèreté car on continue de s'amuser malgré les combats et la mort. Le dessin de presse se charge alors de valoriser le Poilu tout en mettant en scène les souffrances quotidiennes et en exprimant parfois une certaine réserve sur la guerre. On critique, bien évidemment, les planqués de l'arrière. Des journaux de tranchées voient le jour et recourent à des dessinateurs souvent non professionnels. À la Belle Époque, Marianne symbolisait aussi bien la République, la Révolution ou la France dans l'image satirique, tandis qu'elle traduit dorénavant et exclusivement la Patrie, opposée aux Boches, à Germania ou encore à Guillaume II. En dehors de toute culture guerrière, se fonde alors Le Canard Enchainné qui défendra des positions plutôt pacifistes, avant de se rapprocher des idées du parti communiste au moment de l'entre-deux-guerres.

Pendant l'entre-deux-guerres justement, perdure la profusion des journaux à caricatures. Par contre, le métier de dessinateur évolue. Christian Delporte a beaucoup insisté sur l'idée que les caricaturistes ne se considèrent plus alors comme des artistes, mais comme des journalistes. Certains d'entre eux passent en effet plus de temps dans les couloirs du palais Bourbon et dans les rédactions que dans les ateliers. On expose au Salon des humoristes sans chercher à faire carrière dans le grand art. Le dessin politique et parlementaire vise au dépouillement graphique. Pour autant, bien des dessinateurs restent encore attachés à une certaine richesse formelle, surtout dans les hebdomadaires. On pense à Iribe par exemple et à ses charges dont les couleurs, traitées en à-plats, sont fortement teintées d'esprit Art déco. Sennep à droite et Cabrol à gauche tiennent alors le haut du pavé. Le premier illustre ce nouveau rôle du dessinateur-journaliste, publiant à L'Action Française et à Candide. Le second reste héritier de la tradition du portrait-charge et travaille pour le parti communiste. Le clivage gauche/droite structure encore très fortement la presse satirique. Certains stéréotypes perdurent, comme le juif enrichi. D'autres font leur apparition, comme le bolchevik. On joue dorénavant avec les symboles 
des partis. Le dessin intègre en cela les expériences de l'abstraction. La faucille et le marteau, le triangle, le compas et les trois points maçonniques, ou encore l'étoile de David et les trois flèches socialistes structurent bien des images.

La Seconde Guerre mondiale ne présente pas une grande originalité par rapport aux périodes qui précèdent si ce n'est, bien sûr, l'engagement de certains dessinateurs français aux côtés des nazis, comme Ralph Soupault. À la libération renaît une presse dynamique et variée, qui n'hésite pas à faire appel aux dessins satiriques. Dans les années 1950 se développe l'humour graphique, notamment à Paris Match, comme on l'a vu. Depuis cette époque, ce qui s'est maintenu, c'est le dessin politique dans les quotidiens nationaux. Le Figaro avant la mort de Faizant, Le Monde, Libération en sont les exemples types. La presse quotidienne régionale n'est pas en reste avec ses dessinateurs attitrés. Par contre, ce qui est nouveau, c'est la disparition des hebdomadaires satiriques spécialisés. Certes, on pourrait citer quelques titres contestataires célèbres qui ont marqué les cinquante dernières années, comme Siné Massacre, L'Enragé, ou La Grosse Bertha. Pinatel à l'extrême-droite, un moment, publiait Le Trait, totalement illustré. On pense aussi à Hara Kiri et à son humour particulier, utilisant beaucoup la photographie. Malgré tout, depuis les années 1960, le dessin de presse a trouvé des débouchés dans les magazines. Minute, en son temps, a accueilli des dessinateurs de premier plan. Marianne, aujourd'hui, publie de nombreux dessins commentant l'actualité politique et sociale. Mais actuellement en France, seuls Le Canard Enchaîné, Charlie Hebdo et, depuis peu, Siné $\underline{H e b d o}$, ressemblent à certains de leurs ancêtres du XIx ${ }^{e}$ siècle.

Le dessin de presse, après la Seconde Guerre mondiale, a perdu en audience par rapport aux périodes qui précèdent. Paradoxalement, au moment où en Occident l'image satirique perd du terrain, elle en gagne dans le reste du monde, notamment depuis la décolonisation. Dans presque tous les pays du monde, on trouve dorénavant du dessin de presse, qui doit vivre parfois dans des conditions difficiles. On s'interroge sur l'influence d'Internet sur ces images. En fait, depuis longtemps, le dessin satirique a été confronté à de nouveaux médias, s’y adaptant en général avec un succès limité. Le cinéma, dès avant 1914, diffuse des caricatures filmées pendant les séances d'actualité, comme celles du dessinateur Léonard. On a un autre exemple avec l'un des nombreux petits films conservés par les archives Pathé, un film où le dessinateur tourne toujours le dos à la caméra : il dessine sur un écran noir à la craie et parfois, il intervient comme acteur, il regarde le spectateur, fait des clins d'œil, joue sur le suspense... On se demande ce qu'il va devenir, le skieur! Ça dure en gros une minute. Le dessinateur n'est pas français, a priori il est allemand ou autrichien, mais ces séquences passaient en France. On imagine qu'il y avait de la musique, du piano. Ensuite, on est un peu perdu. Le dessinateur signe à l'envers et patatra! Voilà qu'il retourne son dessin!

Plus proche de nous, l'image satirique s'est invitée à la télévision dans l'émission Tac au Tac avec un jeu entre plusieurs dessinateurs, et aussi au Petit Rapporteur et à Droit de Réponse. Le 20 heures, également, a eu recours au dessin de presse filmé. La caricature a trouvé un nouveau souffle avec les marionnettes du Bébête Show importé d'Angleterre et, plus tard, avec 
Les Guignols. À la fascination qu'entraîne l'efficacité de la charge en relief, s'ajoutent le mouvement et le son qui permettent d'entrer dans le monde captivant de la fiction.

Mais la grande révolution du support depuis quelques années, c'est bien sûr Internet. Comme la presse l'a permis depuis 1830, Internet donne, de manière vertigineuse, une audience encore plus large au dessin satirique. La caricature publiée dans un journal se retrouve presque immédiatement sur la Toile, qui permet aussi la mise en ligne d'œuvres inédites. D’un clic, l'internaute accède à une planche à dessin mondiale où chacun s'exprime dans ou hors de son pays, contournant les interdits avec, forcément, tous les travers et tous les bienfaits que l'on connaît. La diffusion lointaine et rapide des images entraîne une ouverture sur le monde et également un choc des cultures. L'image satirique, instrumentalisée dans le cadre des rivalités entre États, trouve, quand elle est rediffusée par la télévision ou le web, une nouvelle manière d'alimenter les tensions interculturelles. On pense à l'affaire des caricatures de Mahomet ou au concours organisé en Iran sur la Shoah. Internet, pour l'instant, semble ne modifier ni les sujets ni le langage du dessin de presse. Les dessins publiés dans le journal papier ou sur la Toile sont interchangeables.

Pour terminer notre panorama, évoquons un dernier aspect : au-delà de la production et de la consommation du dessin de presse, quel statut chaque période que nous venons d'évoquer a-t-il attribué à ce genre ? Quand naît la caricature en Italie avec les frères Carrache, très vite se publient des recueils. Des esprits éclairés cherchent à analyser cette nouvelle manière comprise comme, finalement, l'envers de la quête du beau idéal. En 1792, le journaliste et polémiste Boyer de Nîmes, de tendance royaliste, reproduit et analyse une série de caricatures patriotiques. L'auteur - et c'est un point de vue original $-s^{\prime}$ interroge sur l'influence de ces gravures sur les opinions. Il leur attribue un rôle majeur pendant la crise révolutionnaire. Les beaux esprits du XIX ${ }^{e}$ siècle adoptent en général un point de vue négatif, voire hostile vis-à-vis du dessin de presse, considéré comme sulfureux et indigne des cimaises. Quelques personnalités aux idées avancées adoptent un point de vue opposé, comme Baudelaire qui voit dans Daumier un monument de la caricature et de l'art moderne.

Au milieu du XIX ${ }^{\mathrm{e}}$ siècle, le littérateur Champfleury se fait historien de l'image satirique, un historien républicain et militant, qui considère la caricature comme un instrument au service de l'émancipation des citoyens et comme un art qui permet une démocratisation des images. Quand une crise politique ou sociale revigore la caricature, les amateurs éclairés composent des recueils, redoutant que le temps ne fasse disparaitre ces produits éphémères de la mémoire collective. Ainsi en est-il de Jean Berleux qui publie, en 1890 , un catalogue des placards parus en 1870 et 1871. De même, les collections privées de la fin du XIX ${ }^{\mathrm{e}}$ siècle alimenteront les fonds de nombreuses bibliothèques.

En 1888, se tient au Musée des Beaux-Arts de Paris une exposition qui montre une certaine évolution dans le regard porté sur la caricature. L'exposition s'intitule "Exposition des peintures, aquarelles, dessins et lithographies des maittres français de la caricature et de la peinture de mœurs au XIX ${ }^{\mathrm{e}}$ siècle ». L'événement étonne par la renommée de ses orga- 
nisateurs. Plusieurs ministres, des inspecteurs des Beaux-Arts, des conservateurs et des directeurs de musées ainsi que des écrivains, des artistes et des directeurs de journaux parrainent l'événement. Mais si la République officielle et modérée rend hommage à un genre qui a envahi le quotidien des populations, elle émet tout de même bien des réserves. Les maîtres de la caricature, présentés au public, tous décédés, le sont avant tout pour leur qualité d'artistes justement, de peintres habitués des Salons. L'auteur du catalogue, Paul Mantz, montre un certain mépris pour les gravures de la Révolution française. Il oppose - je cite - les «maîtres véritables aux faiseurs d'images qui méritent à peine le nom d'artistes ». Malgré ces réserves, en cette fin du XIX ${ }^{\mathrm{e}}$ siècle, après des décennies de mépris des élites pour la caricature, cette exposition se montre résolument moderne dans son choix d'intéresser le public à ce genre sulfureux.

L'année 1888 confirme un revirement. Le grand amateur d'images satiriques John Grand-Carteret publie alors un ouvrage important, Les Mœurs et la caricature en France, dans lequel il retrace l'histoire de ce qu'il considère comme un genre à part entière. L'auteur se moque des tenants du grand art qui méprisent la satire en image et fournit une documentation inestimable pour comprendre l'histoire des nations, les passions politiques et l'état d'esprit d'une époque. Grand-Carteret publie des recueils analytiques de caricatures françaises, belges et allemandes. Il s'intéresse bien sûr au passé mais choisit surtout de montrer les images qui ont marqué son époque sur des sujets comme l'anticléricalisme, Guillaume II, l'homosexualité, l'Asie, la femme, Bismarck, la Triple Alliance, l'affaire Dreyfus ou Émile Zola. À la fin de certains de ses ouvrages, ce passionné n'hésite pas offrir au lecteur des notices biographiques de dessinateurs, voire un index descriptif des journaux publiés. John Grand-Carteret n'est pas un cas isolé mais c'est un précurseur. À la Belle Époque se publient de nombreux ouvrages s'intéressant surtout aux caricaturistes en vogue, montrant par là le prestige de ces hommes.

Il n'est pas possible de citer tous ceux qui ont contribué à rendre intelligible l'histoire de la caricature et du dessin de presse. Signalons néanmoins un seuil qui se franchit avec André Blum, un historien d'art, cette fois. Blum publie dans les années 1920 plusieurs ouvrages sur la caricature, et aussi sur la gravure, le grand art, l'histoire du costume, etc. Puis, avec Werner Hoffmann en 1958, et son ouvrage La Caricature, de Vinci à Picasso, on insiste, pour la première fois sans doute, sur l'évolution des styles de la caricature et leur influence sur certains mouvements artistiques, notamment sur le réalisme et même l'expressionnisme. On assiste alors à un véritable renversement par rapport aux périodes qui précèdent. Dans les années 1960, Michel Ragon publie un ouvrage sur le dessin d'humour où il étudie la naissance de l'humour graphique d'après-guerre, en le mettant en perspective par rapport au passé. Mais pour caractériser le dessin satirique du $\mathrm{xIx}^{\mathrm{e}}$ siècle, l'auteur prend le contre-pied de ses prédécesseurs. Proche des anarchistes, il estime que l'image satirique s'est toujours montrée réactionnaire : elle s'est attaquée aux innovations techniques et a flétri les nouvelles écoles artistiques, comme l'impressionnisme. 
La caricature et le dessin de presse sont également redevables à des spécialistes de l'image, conservateurs de grandes bibliothèques, comme Jean Adhémar ou Michel Melot ${ }^{21}$. Ce dernier a cherché tout particulièrement à analyser le fonctionnement du rire dans l'image satirique. Dans la foulée de 1968, cet auteur analyse l'histoire de la caricature sous l'angle marxiste, qui n'est plus tellement à la mode, notamment à propos de la réception de l'œuvre de Daumier qui a, même après sa mort, longtemps rebuté la bourgeoisie modérée.

Les historiens et les historiens d'art de la deuxième moitié du XIX ${ }^{e}$ siècle ont jusque récemment boudé ces images de seconde zone, tout juste bonnes à illustrer tel ou tel événement du passé, tel ou tel manuel scolaire. Avec l'histoire culturelle qui s'impose au milieu des années 1980, le mouvement s'est inversé et les historiens se sont mis à voir dans ces images un matériau important permettant d'analyser l'évolution des représentations mentales et des imaginaires collectifs. Maurice Agulhon par exemple, dans sa trilogie sur Marianne, n'a pas manqué de donner une place à l'analyse des caricatures. On pense également aux travaux de Christian Delporte, à ceux de Bertrand Tillier et aux recherches d'Annie Duprat. On ne s'intéresse plus seulement aux thèmes de la caricature ni à sa chronologie. On analyse dorénavant les images de manière transversale. On s'intéresse aux procédés de la satire graphique. On essaie également d'étudier la réception des images, pas toujours faciles à saisir. Ces dernières décennies ont vu se créer des équipes de recherche autour du rire et de l'image satirique, notamment Corhum avec la revue Humoresques et l'Eiris, dont je recommande le site, et la revue Ridiculosa.

En dehors de l'université, des dessinateurs ou des amateurs travaillent à faire vivre la mémoire du dessin de presse. Je pense, par exemple, au Dico Solo, qui représente un outil colossal sur les caricaturistes et les supports existants depuis deux siècles. Même si Beaubourg, la BnF, la BDIC et le Musée d'art et d'histoire de Saint-Denis organisent parfois des expositions sur la caricature et même si, plus récemment, un rapport a été commandé sur la promotion et la préservation du dessin de presse, il faut bien dire qu'en France les grandes institutions culturelles se montrent plutôt frileuses vis-à-vis du genre. Aucun grand musée n'est consacré à la caricature dans notre pays. Les grandes expositions se font rares. Le bicentenaire de la naissance de Daumier, vous l'avez remarqué, a été quand même très modeste. Cette frilosité n'est pas sans conséquence sur la conservation des collections existantes et leur mise à disposition du public. Le papier journal du XIx ${ }^{e}$ siècle est, en fait, très fragile, les collectionneurs le savent bien. Il n'existe, en France, aucun grand plan de numérisation institutionnel s'intéressant particulièrement à l'image satirique. On trouve, bien sûr, quelques documents satiriques sur Gallica, mais assez peu par rapport à l'ensemble. D'autres pays commencent à s'inquiéter du problème. L'université de Heidelberg, en Allemagne, a mis en ligne, par exemple, l'intégralité du journal satirique Kladderadatsch. En Italie existent également de tels projets. Pour l'historien de la caricature, Internet, en permettant l'accès à des collections numérisées complètes, représente une véritable révolution. Il faut aussi se pencher sur l'avenir des collections personnelles des dessinateurs, qui devraient pouvoir trouver une institution pour les conserver et les rendre accessibles aux chercheurs comme au public. 
Finalement, les historiens s'intéressent de plus en plus à l'image satirique au moment où ce mode d'expression semble en perte de vitesse. La presse écrite a perdu en audience au profit de la télévision. L'image fixe perd de son pouvoir de séduction et devient ringarde au regard de l'image animée. Le rire trouve des supports plus attractifs que le dessin d'humour. La satire littéraire et dessinée des siècles passés est remplacée aujourd'hui par les films d'animation ou des séries télévisées qui puisent dans l'humour leur ressort principal. On pense aussi aux comiques dont on rit des facéties en regardant un DVD. Disparues, les feuilles volantes et les cartes postales illustrées de charges vivifiantes vendues par les colporteurs et diffusées par les militants. Disparus, ces dizaines, voire ces centaines de titres satiriques qui égayaient les kiosques à la Belle Époque et reflétaient toutes les sensibilités de l'échiquier politique ou sociologique. Disparue, ou presque, la passion pour ces images qui poussaient le lecteur à les collectionner.

Le dessin satirique est devenu une sorte d'auxiliaire, certes incontournable, de l'expression journalistique. Il vaut parfois un édito mais fait-il encore peur? On peut en douter quand on voit Jean-Louis Debré organiser une exposition de caricatures à l'Assemblée nationale en 2004, signe que le genre a été intégré, qu'il ne porte plus en lui la subversion. Parfois, néanmoins, des réactions hostiles de certains groupes de pression laissent à penser que l'image satirique dérange encore. Il y a là, peutêtre, un danger pour le dessin de presse. L'image satirique pourrait être tentée par l'autocensure. Dans nos sociétés démocratiques en apparence ultra-policées, ne cède-t-on pas, petit à petit, au désir d'évacuer toutes les outrances, pour de bonnes comme pour de mauvaises raisons? Le dessinateur ne peut pas ne pas s'interroger sur ces questions.

En définitive, le dessin de presse subit la dépolitisation générale et l'affaiblissement des clivages politiques. L'effervescence des Trois Glorieuses, de la Belle Époque ou des Années folles n'est plus qu'un souvenir. Pour l'historien qui compare la situation actuelle au passé, les imaginaires d'aujourd'hui semblent surtout marqués par un rapport au monde plus distant. Le dessin de presse ne représente plus le meilleur moyen de mettre en images les opinions, les peurs, les joies et les haines de l'humanité. Les plus pessimistes diront que l'avenir de la caricature se trouve dans les musées, que ce mode d'expression doit être conjugué au passé. Pour les optimistes, plus que l'avenir, toujours difficile à imaginer, ce sont les enjeux du présent qui doivent être analysés. Dans quelle mesure la crise de la presse actuelle - ou peut-être, d'ailleurs, la crise tout court - modifiera-t-elle le rôle du dessin satirique et le travail des dessinateurs ? Internet apportera peut-être des solutions alternatives en termes économiques, comme c'est déjà le cas avec des journaux qui se diffusent uniquement en ligne ou avec des dessinateurs qui proposent, via Internet, des abonnements pour recevoir un dessin hebdomadaire ou mensuel, ou encore des organismes qui valorisent la production des caricatures en organisant des concours et en promouvant leurs œuvres. L'entretien avec Charb et le débat qui va suivre nous éclaireront sûrement sur ces importantes questions, qui en appelleront d'autres, sans doute. 
Je tiens à remercier François Forcadell qui m’a invité ici, ainsi qu'Alban Poirier qui m'a aidé à préparer cette petite conférence, les archives Pathé, bien sûr, qui nous ont autorisé à diffuser les petits films, la Bibliothèque historique de la Ville de Paris et, bien évidemment, les collectionneurs qui m’ont donné accès à leurs inestimables trésors.

François Forcadell : Je voulais moi aussi remercier la Bpi d'avoir invité Guillaume Doizy pour cet historique complet. 


\section{Entretien}

\section{Charb* et François Forcadell}

François Forcadell : Je vous présente le dessinateur Charb...

Charb : Bonjour !

François Forcadell :... de son vrai nom Stéphane Charbonnier, mais ça reste entre nous! Vous avez entendu les fortes paroles de Guillaume Doizy, qui vous a démontré que pour le dessin de presse ou la caricature - personnellement je travaille dessus depuis des années - on n'arrive pas à trouver une définition du métier. Donc, nous allons parler de caricature: ça englobe pas mal de choses. Guillaume Doizy vous a montré que c'est un métier qui vient de loin, qui s'est renouvelé et s'est régénéré à chaque fois qu'il y a eu des périodes politiques assez fortes et qui, malgré tout, malgré même la crise de la presse et également la crise des vocations - l'une étant liée à l'autre - perdure envers et contre tout. Parmi les dessinateurs d'aujourd'hui, on a quand même des signatures comme Cabu, Willem, Siné et Wolinski. Il y a une large représentation de dessinateurs caricaturistes de qualité. Parmi ces dessinateurs, il y a une nouvelle génération qui n'est pas tout à fait la même que celle qui précède, elle arrive maintenant avec les nouveaux supports. C'est une génération de dessinateurs qui actuellement est dans la quarantaine: Charb, Luz, Riss, Tignous, Faujour, qui est dans la salle - vous le verrez tout à l'heure. Donc, c'est intéressant - à partir du moment où on voulait évoquer l'avenir du dessin de presse - de voir déjà comment on devenait dessinateur de presse. C'est-à-dire qu'on voit toujours l'aspect soit graphique, soit ludique du dessin, mais derrière, il y a quand même un métier, ce sont des gens qui réfléchissent, qui ont eu un apprentissage, même si beaucoup sont autodidactes. C'est un vrai métier et c'est intéressant de voir comment de jeunes dessinateurs ont envisagé justement l'avenir du dessin de presse. Et à travers l'entretien avec Charb, nous allons essayer de voir comment naît une vocation, comment naît un dessinateur de presse et quelles sont les questions qui se posent par rapport aux dessins d'aujourd'hui et par rapport à ce métier. J'ai déjà dit qu'il était rédacteur en chef de Charlie Hebdo, il travaille dans beaucoup d'autres journaux, aussi.

Charb : Juste adjoint !

François Forcadell : Adjoint, je fais chaque fois l'erreur mais c'est prémonitoire, je pense! Comment vient le goût du dessin?

Charb : C'est dur à dire, enfin un 20 peu comme pour tout le monde, c'est-à-dire qu'on aime le dessin en mangeant du dessin, en fréquentant le dessin.

François Forcadell : $\mathrm{Au}$ tout départ?

Charb : Étant mômes, tous les gosses ont à peu près le même accès aux dessins, aux illustrés, aux albums de coloriage, aux bandes dessinées, en tout cas la plus grande partie des gamins, je pense. Ensuite, la différence se fait, à mon sens, après le collège. Les gamins ont encore les moyens de s'exprimer au collège dans les cours de dessin. Ça peut être des cours magistraux un peu chiants, mais ça peut être aussi, suivant les professeurs, des cours plutôt intéressants. Même la bande 
dessinée peut être enseignée. Mais après le collège, non seulement il n'y a plus d'apprentissage du dessin mais il n'y a plus non plus de lecture du dessin. La différence, c'est que - enfin, je le pense - le dessinateur de presse en devenir se débusque au niveau du collège. Mais le goût du dessin, je l'ai eu comme tous les gamins l'ont eu, il me semble.

François Forcadell : Quelles ont été tes influences graphiques?

Charb : Tintin d'abord, Picsou ensuite, mais je n'ai pas l'impression d'avoir gardé grand-chose, graphiquement, de ces influences. Là où je commence à me reconnaître chez des anciens, les premiers dessins qui m’ont marqué et qui me marquent encore, ce sont les dessins de Poirier. Je ne sais pas si tu vois qui c'est? C'est un dessinateur de Pif que j'ai cherché à imiter graphiquement et je crois qu'il m'en reste encore quelque chose. J'en parlais avec Luz récemment, lui aussi est influencé par Poirier. Lui, ça se voit un peu moins. Et après, à dix, douze ans j'ai essayé d'imiter Cabu avec une certaine rage mais j'ai totalement échoué. Là, je n’ai strictement rien gardé du talent de Cabu !

François Forcadell : Charb n'a peut-être rien gardé de $\mathrm{Cabu}$, mais quand on voit le dessin sur la ministre...

Charb : Qui normalement est en fuschia!

François Forcadell : Mais même en noir et blanc elle est reconnaissable! Est-ce que les lectures sont importantes quand on est jeune, sous influence ? On a vu que c'était Pif...
Charb : Le tournant dans la bande dessinée - puisque enfin, étant môme j'essayais plutôt d'imiter les dessinateurs de bande dessinée et de m'exprimer en cases et en bulles... - la différence, elle s'est faite avec la découverte de Cabu, ses albums et son Grand Duduche, qui n'étaient pas tout à fait de la bande dessinée parce que il n'y avait pas de cadres, pas de cases, l'enchaînement était assez libre. Il pouvait y avoir une forme bande dessinée mais pas seulement. Alors, c'est par Cabu que j'ai fait la jonction entre la bande dessinée - ou l'expression qui ressemble à ça - et le dessin de presse. C'est par les bandes dessinées, par Le Grand Duduche de Cabu que je suis arrivé à son dessin de presse et que là, j'ai découvert l'univers du dessin de presse.

François Forcadell : C'était les albums? Les journaux, aussi ?

Charb : Les journaux, c'était un peu Entretien avec Charb difficile, parce que j'étais trop jeune pour connaitre Charlie Hebdo et que le jour où j'ai commencé à le lire, le dernier numéro paraissait. Donc j'ai eu droit à la couverture "Allez vous faire enc... » J'y suis allé avec plaisir !

François Forcadell : Tu n'avais pas compris!

Charb : Si ! Mais comme journaux satiriques, en tout cas avec du dessin de presse, il n'y avait guère que le Canard Enchaîné. C'était un peu décevant, disons qu'il fallait s'intéresser de très près à la politique française pour comprendre le sens de ces dessins. J'étais plus sensible à des dessins beaucoup plus généraux sur l'actualité mondiale, contre la guerre, la faim dans le monde, etc. 
François Forcadell : Dès le départ, tu étais intéressé par l'actualité, le dessin de société ?

Charb : J'y suis arrivé par Cabu. J'étais totalement fasciné par lui.

François Forcadell : Mais Le Grand Duduche, ce n'était pas très politique, à l'époque !

Charb : Un petit peu quand même.

François Forcadell : Ça commençait à être un peu politique...

Charb : Contre l'armée. Et puis, je me suis intéressé aux dessins politiques d'actualité française par Cabu, attiré et fasciné par son trait, la virtuosité qu'il avait - et qu'il a toujours. J'étais vraiment amoureux du dessin de Cabu. Donc, partout où je pouvais trouver du Cabu, j'en achetais, que ce soit des dessins d'actu ou de la bande dessinée.

François Forcadell : Comment viton quand on est encore collégien à l'époque, entre le dessin qu'on apprend au collège et ce qu'on voit à l'extérieur ? Est-ce qu'on arrive à faire le lien entre les deux? Parce que l'enseignement artistique formate, en général...

Charb : Le lien s'est fait. C'était moins de l'enseignement artistique qu'une grande récréation où il nous était permis de dessiner plutôt que faire d'autres choses. Mais je ne pense pas avoir appris grand-chose au collège en dessin. La seule chose que j'ai retenue de la part des profs, c'est de m'entendre dire qu'il n'y avait absolument aucun avenir dans le dessin de presse, que la bande dessinée, déjà, c'était limite mais alors, le dessin de presse, il fallait totalement laisser tomber! Que surtout, je ne rêve pas de faire une carrière là-dedans! Ça a été, pendant toute ma scolarité, jusqu'à la fin du lycée, la même rengaine. C'est-à-dire qu'à chaque fois que j'avais des adultes responsables devant moi, il n'y en avait pas un seul qui m'y encourageait, sauf une prof au collège où je travaillais pour le journal, qui m'a dit: "On s'en fout, vas-y, fonce!» Mais sinon, tous les adultes, y compris ceux qui étaient censés être les professionnels du dessin, enfin les profs de dessin, etc., m’ont toujours découragé dans cette voie.

François Forcadell : Mais pour le contenu ou pour le trait? Ou pour les deux?

Charb : Le problème c'est que ça ne rentrait dans aucune case. À l'époque, quand j'étais au collège, il commençait à y avoir des écoles de bande dessinée, ça pouvait effectivement s'apprendre dans une école, donc l'institution reconnaissait la bande dessinée comme un boulot praticable puisque il y avait des écoles pour ça. Pour le dessin de presse, il n'y avait pas d'écoles et même les profs de dessin ne savaient pas dans quelle case ranger un dessinateur de presse. Quelles démarches il fallait faire pour être un dessinateur de presse, quels bagages il fallait avoir, quelles études il fallait faire... Il n'y avait rien et il n'y a toujours rien.

François Forcadell : Et le cheminement se fait comment? Quelles sont les premières publications?

Charb : Les premières publications, c'était, tout bêtement, en mettant en scène des profs ou des des-
Entretien avec Charb 
sins censurés qui circulaient sous le manteau et aussi, publiés dans le journal du collège, des dessins plus généraux sur l'éducation... Puis après, à la fin du lycée, une publication dans un hebdomadaire d'information qui s'appelait Nouvelles $d u$ Val-d'Oise, qui avait trouvé très intéressant de mettre du dessin dans ses pages, pas mal de dessin d'ailleurs. Intéressant, parce que c'était un genre nouveau et original et c'est ce que je pensais aussi. Puis je me suis aperçu que c'était beaucoup moins cher que les photos, donc ils trouvaient ça plutôt sympa de combler les trous avec du dessin plutôt qu'avec des photos!

François Forcadell : Comment bascule-t-on du journal lycéen ou collégien vers le milieu professionnel ? Est-ce qu'à un moment, il faut arriver avec un produit fini ?

Charb : C'est le journal collégien, en gros, qui m'a permis d'aborder le journal professionnel parce que, dans le collège où j'étais, le journal qu'on faisait a reçu quelques prix nationaux, etc., donc la presse locale en a parlé, donc le contact avec les journalistes locaux s'est fait. Puis, au fil des années, j'ai fini par intégrer le journal.

François Forcadell : Est-cequ'après tu as fait la démarche d'aller voir en vrai des journaux ou d'élargir un peu le nombre de titres?

Charb : Oui, bien sûr. Après, c'est la galère de tous les dessinateurs de presse : il faut présenter ses dessins aux journaux professionnels, et puis on va à Paris et on se trimballe avec le carton de dessins. C'est la caricature du dessinateur de presse : je vais à Paris et je me trimballe avec les dessins sous le bras et je fais toutes les rédactions. Je m'étais même acheté un dictionnaire de tous les journaux de presse avec leur adresse. Quel que soit le sujet du journal, j’allais voir le journal et si possible quand il n'y avait pas de dessins dedans - j'allais voir surtout les journaux où il n'y avait pas de dessins - pour en proposer. Quelquefois ça marchait, je réussissais à faire un dessin de temps en temps dans un journal, comme ça. Puis, le journal coulait ou il n'avait plus besoin de moi...

François Forcadell : C'est une période qui dure combien de temps, en général? Enfin, en particulier, dans ton cas!

Charb : En général, je ne sais pas, mais moi j'ai commencé à démarcher les journaux vers 1987 , pour atterrir en 1991 dans un journal qui m'a permis de publier régulièrement, La Grosse Bertha, dont Cabu était le rédacteur en chef à l'époque.

François Forcadell : Donc, ça fait quand même quatre ans pendant lesquels on n'est pas encore dessinateur professionnel...

Charb : En quatre ans, on ne sait pas bien ce qu'on est. Pareil, l'entourage veut bien vous appeler "dessinateur" à condition que vous ayez des diplômes de dessinateur, que vous ayez fait une école de dessinateur. Á part ça, rien de particulier.

François Forcadell : Ou des publications?

Charb : Justement, c'est à force de publications. Encore maintenant, 
j’ai du mal à me dire : « Je suis dessinateur de presse ». Oui, de fait, je suis dessinateur de presse. Mais je suis encore formaté par tous les gens que j'ai fréquentés étant enfant. C'est-à-dire qu'il faut que ce soit sanctionné par un diplôme.

François Forcadell : Oui, mais peut-être que les parutions sont déjà un diplôme en soi, le fait d'être diffusé à plusieurs milliers d'exemplaires.

Charb : Bien sûr, mais il me reste toujours ce truc de ne pas être légitimé par un diplôme ou par un cursus universitaire ou je ne sais quoi.

François Forcadell : Peut-être que le poste de rédacteur en chef serait...

\section{Charb : Même pas !}

François Forcadell : On va parler dessin aussi parce que ça donne envie de s'exprimer, de réagir sur des idées. Comment un dessinateur crée-t-il son style? Comment cherche-t-il son moyen d'expression graphique ? Ça démarre comment, en dehors des influences qu'il a pu recevoir? Je ne pense pas que Poirier ait eu beaucoup d'influence?

Charb : Au départ, on essaie d'imiter. À force de vouloir essayer d'imiter et de ne pas y arriver, on laisse tomber et puis on pique une crise de nerfs et on va au plus simple: on fait ce qu'on sait faire ou à peu près faire, sans se forcer, en essayant d'y aller le plus naturellement possible. On ne maîtrise pas forcément le résultat. Pour moi qui n'ai pas une formation de dessin classique, je peux dire que de 1991 jusqu'à aujourd'hui mon dessin a été en perpétuelle évolution et il ne s'est d'ailleurs pas fixé. C'est toujours le même style, bien sûr. Mais d'année en année on peut voir l'évolution graphique et, à mon sens, ça va vers une amélioration. En tout cas, le dessin bouge toujours un petit peu d'année en année. Je n'ai pas encore réussi à le fixer. Je ne sais pas si je le fixerai un jour.

François Forcadell : Cabu raconte que lui, il aimait les dessins de Grove dans Le Canard Enchaîné, ou de Beuville. Et Siné prend Steinberg comme modèle. Il raconte qu'il a acheté tous les bouquins de Steinberg pour essayer de trouver son style. Il y a beaucoup de dessinateurs comme ça... C'est vrai que c'est un métier d'autodidacte, donc il faut se faire sa propre école... Mais de là à trouver le moyen d'expression le plus efficace, il y a un vrai travail à faire, ne serait-ce que sur le trait, par exemple... Et l'outil, le choix de l'outil ?

Charb : Ce n'est pas un travail conscient, je pense, le choix de l'outil. Moi, j’ai commencé avec de vrais outils de professionnel, des pointes à l'encre de Chine, etc. que je ne savais absolument pas manier, donc le résultat était assez déplorable! Et puis, comme je te disais, à un moment donné, j’ai essayé de faire au plus simple. J'ai pris un feutre, ce qui était le plus simple à manier pour moi, et voilà. Comment naît le style? C'est difficile à expliquer, et je ne crois pas que je serai capable de le faire.

François Forcadell : Dans la mesure où il y a évolution, c'est beaucoup de travail. Je pense qu'on 
évolue aussi beaucoup en publiant, en voyant ses dessins publiés...

Charb : De toute façon, la meilleure formation, c'est le travail. Non seulement il faut dessiner le plus souvent possible, mais en plus, le fait que ce soit publié, d'un seul coup, ça amène à prendre les choses un peu plus au sérieux et on ne fait plus n'importe quoi. À un moment donné, on réfléchit à ce qu'on va faire. On sait que le dessin va être vu et qu'il restera. Le support papier peut être un peu éphémère, mais quand même, il restera. Un jour, on pourra me le remettre sous le nez en disant: "T'as vu ce que tu faisais comme merde! » Donc il faut faire attention, en plus, le fait de publier partout et pas seulement dans des journaux connus... J'ai travaillé dans des fanzines avant...

François Forcadell : Oui, il y a eu Canicule...

Charb : ... le journal auquel a participé Faujour. D'ailleurs, Faujour et moi, on a fait la tournée des journaux parisiens en même temps, à la même époque. Mais c'est une bonne formation. De toute façon c'est vrai sur n'importe quel support aujourd'hui. Et je pense que si j'arrivais maintenant, je dessinerais sur Internet, effectivement, parce que le dessin peut être vu, il n'y a pas de démarches particulières à faire. Il suffit de monter son blog ou son site.

François Forcadell : Quel est le sentiment qu'on éprouve quand on voit son premier dessin publié dans un grand journal ou dans la grande presse? Gineste raconte qu'un jour il a déposé un dessin qu'il avait envie de faire au Monde et le dessin est paru alors qu'il n'y avait que très peu de dessins dans Le Monde. Il ne l'a su que plus tard et après, il a marché à cinquante centimètres audessus du sol pendant trois jours.

Charb : Eh bien! moi, c'est pareil. J'ai vu un dessin publié dans Libération, un supplément de Libération sur des manifs étudiantes. J'avais l'impression que dans le journal, on ne voyait que ça. Je tournais les pages et puis, d'un coup, je tombe sur mon dessin. Évidemment, quel flash!

François Forcadell : Et là, l'entourage, les parents... Ce n'est pas une sorte de diplôme?

Charb : Non! Le diplôme, d'abord, c'est le diplôme.

François Forcadell : C'est un trait de la famille traditionnelle!

Charb : Ce sont des gens qui ne 25 sont pas du tout de ce milieu-là, du milieu de la presse, et moi non plus, je ne viens pas de là. Ce n'est pas tellement le diplôme, c'est: "Est-ce que tu en vis ? Est-ce que tu arrives à gagner des sous avec ça?" Avant de pouvoir dire oui, il se passe quand même un petit peu de temps. Mais à partir du moment où tu arrives à gagner des sous avec ça, ils n'ont plus du tout de jugement sur le trait. D'ailleurs, ils n'en ont jamais eu ni sur le trait, ni sur le contenu, ni sur la forme, ni sur quoi que ce soit. Maintenant, c'est : "Bon, puisque tu vis de ça, c'est que c'est ton métier. »

François Forcadell : Àquel moment arrive-t-on à en vivre ? C'est-à-dire à quel niveau de publication, de collaboration? 
Charb : C'est très variable suivant les gens. Moi, j'ai commencé à en vivre un petit peu bien à La Grosse Bertha. C'était les premiers salaires fixes, réguliers, que je pouvais toucher. Quand on a refondé Charlie Hebdo, en 1992, ce n'était pas de gros salaires, mais ça permettait de bouffer.

François Forcadell : Il faut expliquer aussi que c'est un métier où on vit beaucoup à la pige.

Charb : Oui, c'est le fonctionnement normal...

François Forcadell : C'est-à-dire qu'il y a très peu de journalistes salariés en fixe.

Charb : C'est assez rare. À Charlie Hebdo, tout le monde est salarié, tout le monde a un fixe, ce qui est assez exceptionnel pour la presse.

François Forcadell : Vous êtes combien de dessinateurs à Charlie Hebdo?

Charb : On est onze ou douze.

François Forcadell : On parlait tout à l'heure du trait, de l'image et aussi de l'évolution. Dans quelle catégorie peux-tu te classer en tant que dessinateur de presse?

Charb : Le meilleur !

François Forcadell : Ah ! oui !

Charb: Qu'est-ce que tu entends par là ?

François Forcadell : Par exemple, il y en a certains qui font du reportage. On revient toujours à $\mathrm{Cabu}$, on peut le citer en permanence. Il y en a qui font de la caricature, comme
Bernard. Il y a plusieurs catégories. En plus, on verra tout à l'heure qu'il y a plusieurs sortes de dessins de presse dans la presse.

Charb : Il m’a été donné à Charlie de tâter un peu de tous ces modes d'expression, parce qu'on était censés pouvoir tout faire, en tout cas, on nous donnait la possibilité de tout faire. J'ai fait effectivement du reportage. J'aime bien le reportage, mais à l'évidence, ce n'est pas là où j'étais le meilleur graphiquement. J'avais un style entre le dessin réaliste et le style que j'ai habituellement. Je ne me sentais pas à l'aise là-dedans. À Charlie, toutes les formes du dessin sont exploitées, ça va du strip à la bande dessinée, en passant par le dessin de reportage. Le dessin de presse classique, une case, un texte, une case, c'est là-dedans que je me sens le plus à l'aise. Depuis quelque temps - et de plus en plus - c'est le strip, c'est-à-dire exprimer une idée en trois cases. C'est quelque chose que je vais faire plus souvent. Enfin, si j’ai le temps, je ferai ça plus souvent.

François Forcadell : Ce serait une évolution dans le dessin? On a vu le dessin tout à l'heure avec Guillaume Doizy, c'est toujours très classique. À l'époque, c'était plus artistique, parce que les dessinateurs de presse venaient du milieu artistique, mais le dessin reste toujours assez classique.

Charb : Le seul dessinateur de presse, considéré comme tel, qui ne respectait aucune règle, qui a explosé vraiment le genre, c'est Gébé. Il était capable de changer de style toutes les semaines, pour pouvoir exprimer une idée. Il était prêt à changer de style, de forme d'expression pour se mettre au service de l'idée. 
François Forcadell : On peut dire que tu es un peu plus classique?

Charb : Classique de fait et puis coincé parce que je manque un peu de liberté graphique, dans la mesure où je n'ai pas eu une formation... Cabu a une formation classique. Il peut se permettre des choses que moi, je ne peux pas encore faire. En tout cas, si je me lance dans du dessin de reportage, par exemple, ça ne va pas être très crédible.

François Forcadell : Est-ce que ça limite, ce "manque graphique" ?

Charb : Dans un premier temps, oui. Ensuite, ça stimule un peu parce qu'avec les pauvres outils qu'on a, on est censé essayer d'exprimer ce qu'on a envie d'exprimer, etc. Moi, je fais avec ce que je peux. Le seul souci, c'est que graphiquement, les personnages, les décors, les objets, les voitures, enfin l'univers qui accompagne les personnages, soit cohérent avec eux. Qu'il n'y ait pas une différence de style entre le décor et les personnages. Ça aussi, c'était long à mettre en place parce qu'il a fallu adapter, il a fallu par exemple qu'on puisse imaginer que les personnages que je dessine conduisent les voitures que je dessine.

François Forcadell : Cette mise en place du vocabulaire, elle se fait en fonction de ses moyens, de ses limites? Est-ce que ça évolue aussi ?

Charb : Ça évolue. Tous les jours, j'ai l'impression de découvrir un petit truc. Assez régulièrement, je découvre quelque chose qui me permet de progresser...
François Forcadell : Souvent, quand on voit le dessinateur passer à la télé faire un dessin, on a l'impression que c'est un art instantané. On fait ça en trente secondes parce que l'animateur l'a demandé.

Charb : Le dessin à la télé, de toute façon, il est beaucoup moins chiadé que dans la presse. C'est presque plus de l'écriture que du dessin. Le personnage ou la scène qu'on va dessiner, c'est quelque chose qu'on a déjà programmé à l'avance. On ne se lance pas dans de grandes fresques dans un dessin de télé, d'autant qu'il va être vu trois secondes, même pas!

François Forcadell : Qu'apporte ce support, en dehors de l'audience? Parce qu'entre l'audience d'une émission de télé et l'audience d'un journal...

Charb : Rien de particulier, sauf quand l'émission est en direct, ce qui m'est arrivé chez Fogiel, l'année dernière. C'est vrai que c'est étonnant quand je raconte ça aux copains, parce que beaucoup m'ont demandé ce que j’allais faire làbas. Moi-même, j'avais du mal à répondre. Mais la vraie différence, c'est que l'émission était en direct et que le producteur de l'émission, qui visionne les dessins un quart de seconde avant qu'ils soient publiés ou, en tout cas, qu'ils soient projetés, a joué le jeu. Il m’a laissé une totale liberté. Sur les trente dessins de la soirée, il n'y en a eu que trois ou quatre qui ne passaient pas, et pas seulement pour des raisons de fond, mais parce que je n'étais pas assez rapide à réagir sur un propos. Je ne sais pas si ça aide le dessin de presse, peut-être que ce n'était pas la question, mais c'était amusant 
à faire dans la mesure où il y avait une réaction, notamment quand il y avait des politiques. Il y avait une partie un petit peu politique en début d'émission, après, c'était people, ça, je m'en foutais un peu plus. Mais il y avait des politiques en direct qui voyaient les dessins en direct. Et moi, je voyais la réaction des politiques en direct, pas sur le plateau mais quand ils revenaient en coulisse! Certains jouaient les grands seigneurs: "C'est formidable ce que vous faites!» Mais bon, on s'en fout. D'autres piquaient des crises de nerfs. Il y en a eu deux ou trois qui ont fait la gueule. J'ai été surpris de la réaction des politiques. Je pensais sincèrement que ça leur passait largement au-dessus la tête et qu'ils avaient d'autres chats à fouetter. Certains d'entre eux arrivent à être vexés ou blessés par un dessin!

François Forcadell : Alors, est-ce que la télé n'est pas un nouveau support pour le dessin, avec ce maximum de liberté ?

Charb : Si les règles du jeu sont respectées, c'est formidable. Moi, j'étais très surpris de découvrir - en plus sur M6, dans une émission people - la même liberté que je peux avoir à Charlie, enfin, pas tout à fait, mais c'est ce qui se rapprocherait le plus de la liberté que j'avais à Charlie. Il y a Charlie d'abord, puis l'émission de Fogiel, puis L'Humanité. Ce sont les trois supports avec lesquels j'ai pu m'exprimer le plus librement.

François Forcadell : Il n'y a aucune différence entre les différents supports? L'Humanité est placé au même plan que Charlie ou est-ce qu'il y a des sujets qu'on ne peut pas aborder?
Charb : Il y a des sujets qu'on ne peut pas aborder. Je m'en suis aperçu en les abordant. Critiquer le Parti communiste à L'Humanité, ce n'est pas ce qu'il y a de plus fin à faire! Je m'en suis aperçu assez rapidement! Mais ça ne me choque pas. Que chaque journal ait sa ligne éditoriale avec ses limites, ça ne me choque pas, si les limites sont données au moment où on entre au journal. Ou comme dans l'émission de Fogiel où les règles étaient claires dès le départ. Il y avait des limites. J'ai travaillé un an à Télérama, on m’a dit : "Tu peux faire à peu près tout ce que tu veux, mais pas d'insultes, pas de scatologie et rien sur la religion!" Avec ce qui restait, est-ce que j'acceptais les règles du jeu? Est-ce que j'acceptais de dessiner? Je l'ai fait et j'étais content du résultat.

François Forcadell : Combien de temps?

Charb : Un an. C'était un strip par semaine. Il n'y a rien de plus énervant pour un dessinateur de presse que d'entrer dans un journal - peu importe le support - où le rédacteur en chef ou le responsable vous dit: " $\mathrm{Tu}$ as toute liberté, mais vraiment, tu peux faire tout ce que tu veux!» - effectivement, quand les règles du jeu sont aussi claires que ça, on fait ce qu'on veut - et qu'au bout de deux numéros ou de deux dessins, on nous dit: "Non, il y a des limites! " Là, on peut parler de censure. À partir du moment où les règles sont définies dès le départ et qu'on les accepte, ce n'est plus tellement de la censure. C'est : on respecte ou non la ligne éditoriale d'un journal. 
François Forcadell : Quand on est dessinateur-auteur - puisque tout à l'heure, on verra aussi qu'il y a des illustrateurs qui ne font qu'agrémenter un article - on va forcément vers des journaux qui sont susceptibles de laisser la possibilité de s'exprimer. Est-ce qu'il y en a beaucoup en dehors de Charlie, de L'Humanité?

Charb : Chaque journal a sa petite niche avec son dessinateur qui peut s'exprimer dans une certaine mesure. Un copain m'a demandé de travailler pour une revue qui s'appelle Bateau, elle est donc spécialisée dans les bateaux, à voile plus précisément. Une fois par mois, il y a un courrier des lecteurs et je fais un dessin pour ce courrier. Je dois illustrer le courrier des lecteurs mais, en même temps, j'ai une certaine latitude. Je peux faire du Charlie Hebdo dans le cadre du courrier des lecteurs de cette revue. C'est assez inattendu et ça me redonne un peu espoir dans le dessin de presse. Il y a encore des endroits où on peut faire du dessin sans être trop emmerdé.

François Forcadell : Tu peux expliquer la frilosité des rédactions à utiliser le dessin?

Charb : Tout simplement, ils sont analphabètes! Il y a encore quelques années, il y avait des directeurs artistiques à peu près dans tous les journaux. Le problème, c'est que les directeurs des journaux ou les rédacteurs en chef sont aussi analphabètes en dessin que les lecteurs le sont la plupart du temps. Peutêtre parce qu'ils n'en voient pas! Parce qu'on apprend à lire et à écrire durant toute sa scolarité, mais on n'apprend pas à lire ou à décrypter du dessin. D'où le problème avec les caricatures de Mahomet qui ont été publiées dans Charlie. Pour expliquer à des gens qui n'ont pas l'habitude de voir du dessin que ces dessins n'étaient pas racistes, qu'ils n'étaient pas insultants, c'est très compliqué ! Il faut faire une explication de texte qui fout complètement en l'air le dessin!

François Forcadell : On va lâcher le mot: est-ce qu'il n'y a pas une autocensure des journaux, au moins une frilosité des journaux, pour ne pas choquer le lectorat?

Charb : La réaction la plus terrible que j'ai entendue, c'est quand je cherchais du boulot justement, quand je faisais ma tournée des journaux. C'était un journal médical ou paramédical. C'est la première fois que j'ai été accueilli avec autant de rires, d'éclats de rire. J'ai apporté mon dossier de dessins. Toute la rédaction était morte de rire, ils se les passaient entre eux et c'est remonté comme ça jusqu'au directeur. Je me suis dit: "C'est bon, ça y est, j’ai trouvé du boulot!» Puis ils m’ont rendu tout le tas de dessins, en s'essuyant vraiment les yeux de rire et ils m'ont dit: "Nous, ça va, mais nos lecteurs ne comprendraient pas!» Donc, la tendance des journaux, des rédacteurs en chef et des dirigeants de journaux, c'est de prendre les lecteurs pour beaucoup plus cons qu'ils ne le sont eux-mêmes! C'est assez agaçant! Je ne sais pas si c'est uniquement parisien, mais c'est une tendance assez générale.

François Forcadell : C'est une tendance assez généralisée dans la mesure où il n'y a pas beaucoup de dessin dans la presse de province. Tout est concentré à Paris. 
Charb : Et puis, encore une fois, il n'y a plus de directeur artistique. Quand je suis entré à L'Humanité, il $y$ avait un directeur artistique. Il n'y en a plus maintenant.

François Forcadell : On verra tout à l'heure avec Libération, et notamment avec le travail de Willem, qu'il $y$ a encore des directeurs artistiques et qu'ils utilisent beaucoup le dessin. Quand on parle de l'avenir du dessin de presse - parce que tu es relativement jeune...

\section{Charb : Merci !}

François Forcadell : Quand on voit que certains font des carrières jusqu’à 80 ans et qu'ils créent encore des journaux, il te reste, disons, 40 ans de carrière. Comment te vois-tu, comment te projettes-tu au niveau des supports et du contenu?

Charb : Je n'en ai aucune idée. Je ne sais pas sur quel support je travaillerai dans les années qui viennent. Mais je sais que je continuerai à dessiner, que ce soit sur Internet ou sur des supports qui restent encore à inventer. Je ne me vois pas m'arrêter de dessiner. Si tous les journaux se ferment aux dessins de presse, si Internet passe à autre chose, je sais que je trouverai un support, même si on est deux à le lire, pour produire du dessin de presse.

François Forcadell : De toute façon, on a vu que dans l'histoire les supports se créaient en fonction des événements, qu'il s'agissait souvent de feuilles qui étaient distribuées dans la rue pour...

Charb : Bien sûr. Comme dans les années 1980-1990 avec Canicule, qui était un fanzine. C'était aussi un exutoire. Enfin je dis souvent que si je n'étais pas dessinateur de presse, avec la liberté que j’ai, je serais peut-être tueur en série, ou j'aurais trouvé d'autres moyens de m'exprimer moins démocratiques!

François Forcadell : Justement, à propos de la diversité, tu dessines aussi pour L'Écho des Savanes et pour d'autres journaux. Comment arrives-tu à assumer ces diverses collaborations? Est-ce que c'est un besoin de diversifier, ou des tentatives pour voir si autre chose ne t'intéresse pas plus que le dessin politique?

Charb : Pour L'Écho des Savanes, c'est plus du dessin d'illustration. C'est un peu ce que je fais dans Charlie, ça n'apporte pas beaucoup plus à ce que je fais par ailleurs. À Fluide Glacial, c'est différent parce qu'ils m’ont donné la place pour faire des strips, plus ou moins régulièrement mais relativement souvent quand même. Enfin, pour l'instant, c'est ce que j'aime le mieux faire. Passer du dessin de presse aux strips, à l'idée à développer en trois cases. Avec le strip, il y a un rythme de lecture différent, il y a une ponctuation différente. Ce n'est pas du cinéma, c'est presque du théâtre.

François Forcadell : Il y a quand même une réflexion sur le travail ? Le dessin d'actualité semblerait limité ?

Charb : Quand j'ai besoin de trois cases pour exprimer une idée d'actualité ou commenter une idée sur l'actualité, j'utilise les trois cases. Parce que je sais que dans Charlie Hebdo, je peux le faire. Mais par exemple à L'Huma, c'est plus compliqué puisqu'il y a un encart qui est 
prévu pour un dessin relativement carré, un dessin classique de presse. Donc, le laboratoire, là où on peut tenter des choses, c'est Charlie et pour trouver la place de les mettre en ouvre, c'est quelquefois Fluide Glacial ou d'autres supports.

François Forcadell : Le fait qu'il y ait si peu de journaux satiriques en France?

Charb : C'est un mystère, parce qu'il y a de la place.

François Forcadell : Il y a de la place... Il y a le nombre de dessinateurs, aussi ? Tout à l'heure, Guillaume Doizy disait que le métier était en perte de vitesse.

Charb : Oui, il est en perte de vitesse parce qu'il n'y a plus de visibilité du dessin de presse. Mais quand la France gagne un match de handball, on s'aperçoit que tous les jeunes s'inscrivent au handball et deviennent handballeurs. Du coup, le niveau du handball en France se met à grimper... Plus il y aura de journaux de dessins de presse, plus haut sera le niveau des dessinateurs de presse et plus il y aura de dessinateurs de presse, c'est sûr. Seulement, pour l'instant, on est très limité.

François Forcadell : Je suis peutêtre moins optimiste. Parce que sur une période de quinze ans justement, depuis La Grosse Bertha, qui était un nouveau journal, il y a très peu de dessinateurs qui sont apparus en dehors de Luz, Riss et quelques autres, ou Catherine, qui est une jeune dessinatrice.

Charb : C'est aussi parce que les supports ne sont pas nombreux! À
Charlie Hebdo, c'est vrai qu'il n'y a pas la queue jour et nuit pour porter des dessins. Mais on pourrait intégrer beaucoup plus de dessinateurs que ça à Charlie Hebdo.

François Forcadell : En fait, c'est le rédacteur en chef ou l'adjoint qui pourrait ouvrir.

Charb : Oui. En tout cas, la manière dont ça marche à Charlie, c'est un fonctionnement un peu particulier. Quand quelqu'un apporte un texte, c'est le rédacteur en chef qui tranche pour savoir si, oui ou non, on publie. Quand le dessinateur apporte un dessin, il faut qu'il se fasse un certain consensus de l'équipe autour du dessin. Du coup, l'examen de passage pour faire accepter un dessin à Charlie est beaucoup plus dur que pour les rédacteurs. Ce qui n'est pas tout à fait normal, ce qui limite aussi les tentatives extérieures.

François Forcadell : Quel regard portes-tu, en tant que rédacteur en chef ou même adjoint, sur les jeunes dessinateurs qui viennent, sur la qualité ? Est-ce que certains viennent d'écoles?

Charb : Il y a les deux. Il y a ceux qui viennent d'écoles. Ceux qui ont une très bonne maîtrise graphique viennent souvent des écoles de bande dessinée et ils ont cette formation. $\mathrm{Ou}$ alors ils sont illustrateurs. Il y a de très bons illustrateurs, graphiquement, c'est magnifique. Mais on ne sait pas quoi en faire, parce qu'ils attendent d'illustrer un propos et n'ont pas forcément de propos à tenir. C'est ce qui manque le plus : que ce soit à la fois graphiquement publiable, agréable, et qu'il y ait un propos. 
François Forcadell : Est-ce que tu te posais ces questions quand tu démarrais, quand tu étais un jeune dessinateur ? Est-ce que tu te posais la question du trait et de l'idée, comme tu viens de le dire?

Charb : Oui. C'est là que je travaillais un peu le dessin de presse. Souvent, on dit qu'il faut que le dessin et l'idée soient en adéquation et comptent à parts égales. Je pars du principe que l'idée compte d'abord. Le dessin, ensuite, n'est qu'une façon de faire passer l'idée et n'est, quelquefois, qu'une ponctuation pour lire l'idée ou pour interpréter l'idée. Mais si je dis ça devant Cabu, je me fais tuer!

François Forcadell : Ah bon, à ce point? Mais est-ce qu'il y a une émulation entre dessinateurs, par exemple à Charlie Hebdo ?

Charb : Oui.

François Forcadell : Vous êtes quand même...

Charb : On travaille un peu les uns sur les autres, donc on voit ce que...

François Forcadell : Ça aussi, estce que c'est une méthode de travail ? On peut parler de la méthode de travail, parce qu'à la belle époque de Charlie Hebdo, chacun travaillait chez soi. Enfin, la belle époque, le Charlie Hebdo d'origine! Chacun travaillait chez soi, apportait sa planche avec, comme disait Cavanna, la volonté d'étonner l'autre. Maintenant, je crois que vous travaillez différemment.

Charb : On travaille en grande partie chez nous, mais le lundi par exemple, qui est le jour de la recherche de la couverture, une grande partie des dessinateurs sinon tous sont là autour de la table. Du coup, on voit le dessin de l'autre se créer. De temps en temps, on repère les trucs, les raccourcis dans une caricature. On voit ce qu'a chopé tel dessinateur et on essaie de l'adapter à notre dessin, nous aussi.

\section{François Forcadell : De copier !}

Charb : De copier, enfin...

François Forcadell : De copier... on va dire, sur Cabu!

Charb : Du coup oui, je crois que le fait de dessiner tous ensemble sert les dessinateurs.

François Forcadell : C'est stimulant?

Charb : C'est plutôt stimulant et puis c'est un peu un grand concours de dessins, sans enjeux ni prix. C'est quand même à celui qui fera la couverture. Finalement, c'est le but du jeu, le lundi en tout cas.

François Forcadell : Le diplôme, quoi ! Est-ce que vous parlez dessin entre vous? Entre professionnels, entre dessinateurs?

Charb : Oui, bien sûr.

François Forcadell : Est-ce que vous parlez du travail de l'autre?

Charb : On parle du travail de l'autre et des influences de chacun, des expos que certains ont vues, etc. Là, par exemple, le dernier gros sujet de conversation à Charlie, c'est l'arrivée de l'album de Gébé qui retrace une grande partie de 
son travail dans Charlie Hebdo de 1992 à 2003. Et c'est fabuleux, on a le résumé de dix ans de carrière en un album. C'est une mine incroyable!

François Forcadell : Ce qu'il y avait de bien aussi chez Gébé, c'est qu’il adorait écrire. C'est vrai que ses chroniques sont un mélange de dessins et d'écriture. Et toi aussi, tu écris?

Charb: Oui, je ne mélange pas aussi... Je n'écris pas à la main, ni dans le dessin.

François Forcadell : Tu ne mélanges pas de la même façon, bien sûr. Quels sont les différents plaisirs que tu éprouves, aussi bien à dessiner qu’à écrire?

Charb: Il y a un plaisir... Je ne tomberai pas dans le côté «Un bon dessin vaut mieux qu'un long discours", "Il vaut mieux un bon discours qu'un mauvais dessin ", etc., mais je ne me passerais d'aucun des deux. J'aurais du mal à me passer d'écrire maintenant et je ne peux pas me passer de dessiner. Mais il y a un plaisir sensuel dans le dessin qui n'existe pas dans l'écriture... C'est physique! On a un stylo à la main, une gomme et quelquefois de la couleur, on a un contact avec la matière qui n'existe pas quand on est devant l'ordinateur et qu'on tape un texte.

François Forcadell : Gébé n’écrivait pas sur un ordinateur, il écrivait à la main.

Charb : Parce qu'il n'a jamais su. Feignasse!

François Forcadell : Il a essayé mais...
Charb : Ah! oui, effectivement... Moi, j'ai mis très longtemps à me mettre à l'ordinateur pour écrire les textes à imprimer. Mais enfin, maintenant, j'aurais du mal à revenir à l'écriture manuelle.

François Forcadell : En écrivant, tu n'as pas l'impression de participer à la guerre qui existe entre le texte et le dessin dans les journaux ? Parce qu'il y a une omniprésence des textes...

Charb : Quand je me suis mis à écrire régulièrement, c'était au relancement de Charlie Hebdo. J'avais déjà écrit un petit texte à La Grosse Bertha. À l'époque, Val m'avait demandé si je ne voulais pas écrire un peu dans Charlie parce qu'on manquait de rédacteurs et que la proportion dessin-texte était en faveur du dessin - à la grande joie de Cabu qui est toujours en train de compter dans Charlie combien il y a de surface pour le dessin et combien pour le texte. Il n'a que sa règle et il compte les centimètres, mais, des fois, il s'énerve! Val m'avait donc demandé si je ne voulais pas écrire. Du coup, je me suis essayé à ça et, entre-temps, les années passant, d'autres - des vrais journalistes, on va dire des journalistes d'investigation - ont intégré Charlie Hebdo et ont bouffé un peu la place du dessin.

François Forcadell : C'est bien ou ce n'est pas bien?

Charb : C'est bien dans le sens où je ne crois pas qu'aujourd'hui un journal s'achèterait uniquement pour le dessin. Le dessin est assez vite lu. Les gens font la gueule quand ils doivent débourser deux euros pour acheter un journal. La 
particularité de Charlie Hebdo, c'est que, en gros, le texte vient en illustration du dessin. C'est le truc en plus du dessin. On achète Charlie Hebdo pour le dessin probablement, et puis il y a quand même du texte à se mettre sous la dent. Le Canard Enchaîné, c'est presque un peu l'inverse. On achète $L e$ Canard Enchaîné pour les infos, pour les scoops et, coup de bol, il y a du dessin en plus. Ça fait un petit truc en plus à grignoter. Mais je ne crois pas que ça soit une mauvaise chose. Maintenant, il faut faire gaffe et on essaie de faire gaffe.

François Forcadell : À l'équilibre?

Charb : À l'équilibre, oui ! Il ne faudrait pas que le texte l'emporte sur le dessin et, notamment, si ce sont des textes qui peuvent être lisibles dans d'autres supports, dans d'autres journaux.

François Forcadell : Quand on écrit un texte, est-ce que l'idée est toujours primordiale comme dans le dessin? C'est la recherche de l'idée ou l'expression ? Parce qu'un dessin, c'est aussi un vocabulaire. S'il doit y avoir une chaise, comme on l'a vu tout à l'heure, il faut que ça rassemble à une chaise. S'il y a un tas de paille, il faut que ça ressemble à un tas de paille. Il y a cette recherche d'éléments de vocabulaire, il faut faire une phrase, un dessin. Est-ce que le texte, c'est la même recherche pour toi qui es dessinateur et qui écris?

Charb : Oui, on a le souci de faire des textes cohérents, du moins dans le style, qu'il n'y ait pas de rupture de style dans l'écriture.
François Forcadell : Qu'il y ait un parallèle entre le Charb qui écrit et le Charb qui dessine.

Charb : Ça, c'est dur. Je suis incapable de le dire. Il y a une anecdote amusante... Ce n'est pas vraiment une anecdote parce que ça marrive assez souvent, notamment pour les dédicaces. Des gens viennent vous voir en tant que dessinateur. Là, c'est plutôt: "Salut, comment tu vas?" On a droit à une tape sur l'épaule et c'est plutôt sympa... D'autres viennent vous voir en tant que rédacteur. Là, c'est beaucoup plus guindé. Le vouvoiement est presque obligatoire. Il y a une espèce de respect ou de crainte du rédacteur qui n'existe pas avec le dessinateur. Et il y a une proximité avec le dessinateur qui n'existe pas avec le rédacteur.

François Forcadell : Qu'est-ce qu'il faudrait faire pour que les dessinateurs soient plus... non pas honorés, mais respectés dans leur métier? Depuis le début de la discussion, on a commencé avec le diplôme. Là, avec cette anecdote, apparemment, être dessinateur, ce n'est même pas un métier! La question, c'est toujours: "Qu'est-ce que vous faites comme métier, en vrai ?"

Charb : À part dans Charlie Hebdo où, si on enlevait les dessins, les ventes s'effondreraient, je ne crois pas, pour reprendre mon exemple de Fogiel, quà un quelconque moment, si on avait enlevé les dessins, l'émission aurait fait un spectateur de moins. Je ne pense pas que si L'Huma supprime son dessin, les lecteurs partent en masse. C'est toujours le truc en plus, le dessin dans les journaux. Ce n'est pas considéré comme essentiel. Je pense que, de fait, ce n'est pas essentiel, à la vente en tout cas.
Entretien avec Charb 
François Forcadell : À la vente?

Charb : À l'époque où il y en avait un peu plus, les gens n'achetaient pas Télérama pour les dessins, ou alors quelques rares fans.

François Forcadell : Ce n'est pas un journal de dessins. Donc, on nachète pas...

Charb : Oui, mais il faudrait qu'un dessinateur de journal fasse clairement vendre le journal, pour que ce dessinateur prenne de l'importance. Il n'y a que ça qui compte!

François Forcadell : Moi, je parlais de la respectabilité du métier. Si les gens ne viennent pas dans ce métier, si les jeunes ne viennent pas et si même les journalistes considèrent que ce sont des amuseurs mais que ce n'est pas forcément un métier, comment pourraiton gagner cette respectabilité? Alors qu'un ébéniste peut se faire respecter parce quil fait des meubles..

Charb : Quand on rencontre les lecteurs on est quand même respecté. C'est même plutôt sympa qu'il y ait cette espèce de proximité entre le dessinateur et les lecteurs, qui n'existe pas entre le rédacteur et les lecteurs. Moi, je préfere ça. Mais le respect...

François Forcadell : Vous n'avez pas besoin de respect?

Charb : Non, ça va!

François Forcadell : Je parlais du respect professionnel, c'est-à-dire qui permet de faire ce métier et d'ouvrir les portes, qui permet de gagner sa vie...

Charb : Je ne sais pas ce qu'il faudrait. Honnêtement, je ne sais pas.
François Forcadell : C'est comme les artistes de spectacle. Il faut se battre pour se faire sa place. Il y a beaucoup de parallèles avec les acteurs, entre les deux métiers.

Charb : Il y a beaucoup de parallèles, oui. Mais un dessinateur de presse sans support par exemple, ce n'est plus un dessinateur de presse. $\mathrm{Du}$ jour au lendemain, on peut ne plus être dessinateur de presse et tomber totalement dans l'oubli, être rayé de la carte. Personne ne défilera chez vous pour venir vous chercher.

François Forcadell : C'est ce qui arrive actuellement à Dobritz au Figaro, il est le seul qui soit resté après Faizant. Il est toujours au journal, il a un placard, on ne lui demande plus rien. Il est dessinateur fantôme. Il n'est plus dessinateur, il ne sait même plus ce qu'il est. Il est salarié, il touche son salaire.

Charb : Et encore, il a un salaire, ce qui est très, très rare!

François Forcadell : On a fait le tour de ton parcours jusqu'à aujourd'hui ; pour plus tard, on verra.

Si vous avez des questions à poser à Charb - tant qu'on l'a sous la main -, si vous voulez avoir des éclaircissements... S'il y a des choses que j'aurais oubliées sur " comment devenir dessinateur de presse et surtout comment le rester $" . .$.

Public: Si ce n'est pas indiscret de vous le demander, le fait que depuis quelques temps Siné Hebdo, est-ce qu'il existe pour vous un enrichissement, ou au contraire un problème, parce que la concurrence est déjà rude ? 
Charb: C'est ce que je disais à François tout à l'heure: je pense qu'il y a de la place pour deux, trois, voire quatre journaux satiriques en France. Les dessinateurs de Charlie attendaient Siné Hebdo avec une certaine impatience dans la mesure où ça pouvait être une émulation. Faujour, par exemple, travaille à Siné Hebdo. Moi, j'attendais de voir ce que Faujour allait faire dans Siné Hebdo. Il n'y a jamais assez de journaux satiriques. On constate aussi que tout le monde envisage ça sous la forme de la concurrence. On se dit que c'est Siné Hebdo qui va piquer les lecteurs à Charlie. On n'a pas perdu un seul lecteur et Siné Hebdo se vend. Le numéro deux, je crois, s'est vendu à 100000 exemplaires, ce qui est énorme pour un journal satirique. La seule crainte, effectivement, c'était que le public choisisse entre deux journaux. Je pense qu'il y a deux publics possibles pour deux journaux. Il y a peut-être même trois publics possibles pour trois journaux, peut-être quatre, je n'en sais rien. Mais plus il y aura de journaux satiriques et de dessins de presse, mieux les dessinateurs de presse se porteront.

François Forcadell : Le troisième, c'est Le Canard Enchaîné.

Public: J'avais une question concernant le style. Je trouvais qu'il y avait un certain rapport avec Les Simpson. Je ne sais pas si vous vous retrouvez dedans ou pas, dans le style, la façon de traiter la couleur et même au niveau du style graphique.

Charb : Dans la couleur, oui. C'est vrai, le trait a évolué. Ce n'était pas aussi rond, aussi mou il y a quelques années, le trait s'est peut-être un peu arrondi. Les angles étaient beaucoup plus pointus avant. C'est peut-être l'influence des Simpson, je ne sais pas. En tout cas, on me demande souvent pourquoi j'ai fait les personnages en jaune, parce que ça fait penser aux Simpson. Mais à l'époque, je ne connaissais pas les Simpson. Au moment où je faisais des personnages en couleur, je les faisais jaunes. C'était plutôt pour me démarquer de Tignous qui, lui, utilisait toute la palette des roses pour ses personnages. Moi, pendant un moment, j'avais aussi tendance à faire des personnages roses, sauf que j'étais un peu dans les tons de Tignous et que j'utilisais les mêmes feutres que lui. J'ai essayé en vert, c'était un peu moche. Du coup, j'ai mis du jaune sans penser aux Simpson et, du coup, on m'en parle souvent.

François Forcadell : En même temps, il a trouvé un truc pour qu'on remarque ses dessins par rapport aux autres. Même si on pose ce genre de questions, on reconnaît les dessins de Charb, en plus du trait. Là, je vais faire du Bernard Pivot: "C'est le dernier livre de Charb, qui sort ces jours-ci!»

Charb : Merci, Bernard!

François Forcadell : Il y a un dessinateur qui voudrait poser une question. Rousseau?

Rousseau : Oui, tout à l'heure, Forcadell, tu parlais de la légitimité du dessinateur de presse et du respect qu'on doit lui accorder. J'ai remarqué quelque chose, en voyant tous les dessins de Charb qui vous ont fait bien marrer, je me disais : "Si on gardait les bulles et qu'on changeait de dessinateur, est-ce
36

Entretien avec Charb 
que ça n'aurait pas été exactement pareil ?" Et puis, je me suis dit que finalement, peut-être! Alors, je suis arrivé à la conclusion que le dénominateur commun, c'est l'esprit tout court! Tant qu'il n'y aura pas d'écoles d'esprit ni de diplômes d'esprit, on ne pourra pas dire qu'il y a des diplômes de dessinateurs de presse, ou d'autre chose d'ailleurs. J'entends par esprit... Il y a un mot allemand qui le définit, parce qu'en français je ne sais pas comment ça se dit. C'est le witz. Je crois que c'est Wilhelm Reich qui disait : "C'est tellement violent que ça surprend même son auteur. " Voilà, tout à fait! C'est ce que je voulais dire au sujet du dessin de presse. S'il n'y a pas d'esprit, il n'y a pas de dessin de presse. C'est la recherche de l'idée. L'idée avec de l'esprit, forcément, puisqu'il y a beaucoup de composantes dans un dessin. Il y a l'actualité, le dessin, l'idée. Le journal qui le publie compte aussi. Parce que, si un dessin qui a beaucoup d'esprit est publié dans un tout petit journal, on passe à côté...

Public : Tu disais tout à l'heure que pour expliquer le manque de succès du dessin de presse aujourd'hui, on invoquait le problème d'éducation à l'image: à l'école, on n'éduque pas au dessin de presse... Je te rassure un peu, ça se fait maintenant de plus en plus. Il y a un certain nombre d'enseignants en histoire, ou même en lettres qui utilisent le dessin de presse. Mais je ne suis pas sûr que l'argument soit convaincant. Il y a un siècle, quand il y avait tant de dessins de presse, il y avait encore moins d'éducation à l'image et encore moins d'éducation aux dessins de presse. On n'apprenait pas ça à l'école. C'était quand même un peu spontané. Je crois que le problème est beaucoup plus culturel, social. Il est lié à la situation de la société plus qu'à l'éducation des lycéens.

François Forcadell : Il y a un siècle, il y avait quelque chose de très important - on l'a vu dans la mesure où les dessins étaient mal reproduits dans les premiers journaux -, on ne trouvait pas de photos dans les journaux. Ce qui était publié dans les journaux, c'étaient des dessins. Et encore, au début, il n'y en avait pas beaucoup, de dessins. Les dessins étaient imprimés sur des planches à part, pour pouvoir être diffusés. Mais dans les journaux, techniquement, ce n'était pas possible de les inclure dans les colonnes de texte, qui étaient faites avec du plomb. Donc, les gens qui venaient au dessin dans les journaux étaient de vrais dessinateurs, des artistes. Maintenant, il y a une telle concurrence entre la photo et le dessin ! Par exemple dans Siné Hebdo, il y a Delessert. Siné a décidé de publier Delessert, graphiste américain qui vit maintenant aux États-Unis, parce que c'est $\mathrm{du}$ beau dessin. Mais il n'y a pas de journaux qui ont cette volonté d'éduquer le public en montrant de beaux dessins. Je ne dis pas que les dessins de Charlie Hebdo... Enfin, les dessins de presse aujourd'hui, il y en a moins. Je voudrais revenir aux écoles. Apparemment, il y a des écoles qui envisagent le dessin de presse, ou qui sensibilisent en tout cas, au dessin de presse. Il y a une école à Lyon dont un département travaille sur le dessin de presse. Daniel Maja est intervenu, Got aussi, et Mulatier intervient pour la caricature. L'École Estienne, avec le prix Presse Citron y sensibilise éga- 
lement. C'est vrai qu'il n'y a pas de renouveau non plus. Ils sont dans la tradition du dessin, même s'ils sensibilisent.

Charb : Il y a aussi beaucoup de bouquins de classe qui sont édités avec des exemples de dessins de presse, qu'il faut expliquer, etc. Moi, je suis plutôt favorable à ça. Mais on a un débat avec Cabu: il dit que trouver du dessin de presse dans un bouquin de classe, ça va dégoûter les gens du dessin de presse.

François Forcadell : Cabu a des théories bien à lui !

Charb : Pourtant, il ne boit pas!

François Forcadell : C'est une question de Catherine Meurisse, dessinatrice elle-même. Je suis désolé, je dénonce!

Catherine Meurisse : On est plusieurs dessinateurs, il y en a partout dans la salle. Je voulais te demander, Charb, tu vas peut-être devenir rédacteur en chef?

François Forcadell : C'est une question précise!

Charb : Avec le temps, à l'ancienneté, oui !

Catherine Meurisse: Mais quelqu'un va te laisser la place?

Charb : Il faut la prendre.

Catherine Meurisse: Il faut la prendre, et tu vas prendre la place de qui ?

Charb : Le premier qui meurt, je prends sa place!
Catherine Meurisse: Parce que, pour l'instant, le rédacteur en chef, c'est qui ?

Charb : C'est Gérard Biard. C'est quelqu'un qui écrit, qui est de l'écriture. Le match qui existe à Charlie - je dis ça pour rigoler - c'est effectivement la concurrence entre ceux qui écrivent et qui ont des responsabilités et ceux qui dessinent et qui ont des responsabilités.

Catherine Meurisse : Toi, tu as les deux responsabilités, finalement?

Charb : J'écris et je dessine. J'étais légitime - non je déconne... Ça s'est un peu fait par hasard. Celui qui veut la place, prend la place. Il faut s'investir un peu dans le journal, être là un plus souvent et aimer organiser les choses et se faire chier, c'est tout!

Catherine Meurisse: Mon autre 38 question est : est-ce qu'il n'y a pas une contradiction entre le métier de dessinateur de presse et le métier de rédacteur en chef ? Entre le pouvoir et le dessin de presse?

Charb : Je te rassure, le pouvoir est relativement relatif. Là aussi, on a un fonctionnement un peu particulier à Charlie Hebdo. On a de plus en plus de titres effectivement, qui ressemblent à des vrais titres que les gens ont dans les journaux. Dans l'ours de Charlie, il y a marqué : rédacteur en chef, rédacteur en chef adjoint, etc. Mais je n'ai pas l'impression d'avoir les prérogatives d'un rédacteur en chef adjoint. Je ne pense pas que le rédacteur en chef ait les prérogatives d'un vrai rédacteur en chef. On est plus des supersecrétaires de rédaction 
que des rédacteurs en chef, dans la mesure où, en tout cas pour le dessin, je n'ai jamais à orienter le travail d'un dessinateur. Je répartis les espaces dans le journal entre les dessinateurs, mais ce n'est pas moi qui vais faire leur boulot et qui vais déterminer les thèmes à traiter. Les dessinateurs sont suffisamment autonomes et on leur fait suffisamment confiance pour qu'ils soient leurs propres rédacteurs en chef. C'est plus un boulot de secrétariat de rédaction, qui fait quoi et à quel endroit.

Catherine Meurisse : Tu ne te sens pas dans le pouvoir?

Charb : Ça ne me dérange pas d'avoir plus de pouvoir et de l'exercer, sauf que je n'ai pas l'occasion de le faire. Diriger le monde, j’aimerais bien!

François Forcadell : Le journal ?

Charb : Non, l'univers!

François Forcadell : D'autres questions?

Public : J'ai vu la discussion tourner autour du fait de rendre le métier de dessinateur de presse respectable. Mais est-ce que le risque ce n'est pas, en cherchant à rendre respectable le dessinateur de presse, de le priver de son arme principale, qui est l'irrévérence? Faire du métier de dessinateur de presse un métier respecté, est-ce que ce ne sera pas l'enfermer précisément dans une forme de respect qui le désavantagera?

Charb : C'est le problème qu'évoquait le camarade tout à l'heure. Une exposition de dessins de presse organisée par Debré à l'Assemblée nationale, est-ce que le dessinateur de presse doit se sentir flatté de ça ? Je ne suis pas sûr! En même temps, il y a une reconnaissance et du coup, reconnaissance nationale. On en parle au journal de 20 heures. D'un coup, le dessinateur de presse devient important en France, le temps d'une exposition. Mais dans la mesure où les politiques adoubent le dessin de presse, est-ce qu'on est encore crédible dans notre expression de contestation? La question se pose.

François Forcadell : La respectabilité, c'était pour le métier. Quand on reçoit un dessinateur, on le respecte dans ce qu'il fait, dans ce qu'on lui laisse faire. C'est à ce niveau-là que je parlais de respectabilité. Ce ne sont pas des médailles!

Charb : Je comprends ce que veut dire François, je m'en suis aperçu. Quand on travaille à Charlie Hebdo, évidemment on est dessinateur et comme c'est un journal de dessins, on est respecté. On se respecte les uns les autres et on existe. Ma courte expérience à la télé m’a appris aussi l'humilité. En tant que dessinateur de presse à la télé, j'étais vraiment la dernière roue du carrosse. D'une part, j'étais le moins payé de tous les intervenants de la télé et entre la personne qui parle à l'antenne et celui qui dessine dans l'ombre, il y a un univers. On n'est pas traités du tout de la même manière. Pas du tout, du tout! J'étais un bouche-trou, très content d'avoir un trou à boucher, mais je n'étais absolument pas essentiel à la marche de l'émission. Or, le moindre technicien est essentiel à la marche de l'émission, sinon il n'y 
a pas d'émission. Moi, j'étais le truc en plus. De ce point de vue-là, c'est vrai qu'on n'est pas traités à égalité avec les autres professions.

Rousseau : Moi, je pense que la Légion d'honneur qu'on a donnée à Wolinski peut faire honneur à son récipiendaire, mais je ne crois pas que ça honore beaucoup la profession, entre nous.

Charb : Je ne crois pas que Wolinski l'ait fait pour honorer la profession. Je crois qu'il était content d'avoir une décoration à lui tout seul. En tout cas, il ne l'a pas acceptée au nom de Charlie Hebdo, je vous rassure.

Public : Je voudrais dire juste une chose que je ressens par rapport à la place du dessin en France. Je pense que le dessinateur est toujours considéré comme un gamin qui fait rire. C'est l'écrit qui prime et qui est reconnu, qui est respectable, etc. Dans d'autres pays c'est complètement différent, notamment les pays anglo-saxons où là, l'image, le dessin, ont toute leur valeur.

François Forcadell : C'est peut-être ce qu'on va voir dans le débat avec Odile Conseil tout à l'heure. Une question de Guillaume Doizy...

Guillaume Doizy : J'aurais voulu poser une question autant à Charb qu'à Faujour. Je ne sais pas si j’ai le droit de poser une question à Faujour. Je voudrais savoir si vous vous considérez comme des militants. Si oui, des militants de quoi, puisque Faujour travaille à Rouge, par exemple? Quels sont ses rapports avec Rouge?... C'est trop long?
Charb : Enfin, oui et non! Non, parce que, quand je fais un dessin militant, un dessin commandé par un syndicat, un parti politique et que je le fais gratuitement, pour que ce syndicat ou ce groupement politique aient plus de voix ou plus d'audience, je suis militant. Quand je fais un dessin qui parle de politique, ou même un dessin qui peut paraître engagé mais que je suis payé pour ça, je ne me considère pas comme un dessinateur militant. Je n'ai pas l'impression d'être militant dans Charlie Hebdo, dans la mesure où c'est mon travail d'être militant. Je ne pense pas qu'on puisse être un fonctionnaire ou un salarié du militantisme. Le même dessin qui paraît dans Charlie Hebdo par exemple et qui paraîtra gratuitement dans un tract de la CGT, sera un dessin militant dans le tract de la CGT parce qu'il sera publié gratuitement, alors que ce n'est pas un dessin militant dans les colonnes de Charlie Hebdo. C'est éventuellement un dessin engagé ou un dessin d'opinion, mais ce n'est pas militant. Pour moi, le militantisme suppose une certaine gratuité et un certain engagement, de prendre du temps pour la cause.

François Forcadell : Il faut dire aussi que les journaux qui pouvaient publier des dessins militants ont disparu. Chaque parti avait plus ou moins son journal. Le Parti socialiste avait un journal où il y avait beaucoup de dessinateurs. Tout à l'heure tu citais Minute: Minute aussi avait beaucoup de dessinateurs, de droite et d'extrême-droite. Maintenant, il y a de moins en moins de presse d'opinion. 
Charb : Et puis, c'est tellement la dèche chez le dessinateur de presse et le dessinateur de presse politique que Rouge, le journal de la LCR, est obligé d'embaucher un dessinateur non trotskiste!

François Forcadell : C'est Faujour, mais il le devient jour après jour! On va passer au prochain débat pour élargir au dessin dans le monde. 


\title{
Table ronde : Quel avenir pour le dessin de presse?
}

\author{
Alain Blaise*, Charb, Odile Conseil*, Bernard Fournier*, \\ Luce Mondor*
}

François Forcadell : Nous allons entamer la troisième partie de cet après-midi sur le dessin de presse. C'est un événement. Je veux parler de cet après-midi. Je crois que cela fait très longtemps qu’on n’a pas consacré autant d'heures au dessin de presse. Faujour, si tu pouvais arrêter de parler!

Loïc Faujour : Qu'est-ce qu'il y a ?

François Forcadell : Dessine! Tu es là pour dessiner, pas pour parler! Je disais que c'est la première fois depuis longtemps qu'un organisme officiel et aussi important que la Bpi consacre autant de temps au dessin de presse, avec d'éminents spécialistes que je vais vous présenter: Odile Conseil, qui travaille à Courrier International. Courrier International publie beaucoup de dessins qui viennent de l'étranger et, au sein du journal, il y a une agence de presse. Odile Conseil fait aussi une petite émission sur un dessin chaque semaine sur Arte.

Odile Conseil : L'émission est mensuelle.

François Forcadell : J'étais trop optimiste!

Odile Conseil : C'est une émission qu'on peut présenter - pour répondre un peu à ce que disait Charb tout à l'heure - comme ayant une légère vocation pédagogique. Il s'agit de montrer comment un événement de l'actualité internationale est vu par les dessinateurs du monde entier.

François Forcadell : Ils sont aussi diffusés sur le site du Courrier International...

Odile Conseil : Certains sont publiés dans Courrier. Pas tous, parce qu'on reçoit chaque jour une masse de dessins qui ne sont pas tous publiés, mais qui servent éventuellement au site. Et aussi aux éditeurs scolaires, parce que certains en demandent régulièrement. Ils sont stockés pour un usage un jour ou l'autre.

François Forcadell : La vision du dessin d'Odile Conseil est intéressante, parce qu'elle va déjà nous parler de ce qui se fait en dehors de Charlie Hebdo, Siné Hebdo et Le Canard Enchaîné, ce qui élargit le spectre. Maintenant, je vous présente Alain Blaise, qui est directeur artistique à Libération, quotidien français qui a une politique bien affirmée sur le dessin, notamment avec un dessinateur régulier, Willem, et aussi d'autres dessinateurs qui sont plus des illustrateurs des pages du journal. Et c'est Alain Blaise qui dirige tout cela. J'en viens à Bernard Fournier, directeur artistique à L'Équipe Magazine, qui lui aussi a fait travailler beaucoup de dessinateurs dans ce journal: Cabu, Desclozeaux et plein d'autres. Il est également concepteur d'expositions sur le dessin de presse. Il a réalisé l'exposition sur $\mathrm{Cabu}, \mathrm{Cabu}$ et Paris, qui a eu lieu l'an dernier, à la Mairie de Paris, et présentait l'œuvre d'un des plus grands dessinateurs d'aujourd'hui. Il est aussi directeur de collection aux éditions Le Layeur et fait des livres sur des dessinateurs : toujours Cabu, Lefred-Thouron, Willem peut-être, et Honoré bientôt. Il nous parlera de son rapport à l'image et de la présentation de l'image pour toucher un public à travers les livres et à travers les expositions. Je termine avec Luce Mondor, enseignante à l'École Estienne. Elle travaille beaucoup avec les élèves de l'École Estienne, justement sur le dessin de presse et à travers le Prix Presse Citron qui, depuis quatre ou cinq ans...
Table ronde : Quel avenir pour le dessin de presse? 
Luce Mondor : En fait, il est beaucoup plus vieux que ça, il a seize ans. Je suis venue avec mon badge Presse Citron, dont je vous parlerai tout à l'heure. Il s'agit d'un concours de dessins de presse.

François Forcadell : On va commencer par une présentation d'Odile Conseil sur le dessin dans le monde.

Odile Conseil : Il y avait une question sur l'avenir du dessin de presse. J'ai essayé en bonne élève, de répondre à la question, en deux parties même, comme on fait dans certaines grandes écoles, parait-il ! L'avenir du dessin de presse, je pense que dans l'absolu il est brillant. Il est brillantissime parce que le dessin de presse a trois fonctions. Il fait rire, réagir, réfléchir. Ce sont les " $3 \mathrm{R}$ » du dessin de presse. On est dans une période où on a sans doute beaucoup besoin de rire, pas mal besoin de réfléchir et aussi de réagir. Un des dessinateurs allemands que j'ai interrogés sur cette question de l'avenir du dessin de presse - puisque j'ai posé la question à plusieurs des dessinateurs avec qui je suis en contact assez régulièrement - regrette que les dessins de presse, actuellement dans la presse allemande, soient inoffensifs. Ce qui laisse à penser, et je suis assez d'accord avec lui, qu'un dessin de presse doit être offensif.

En gros, je pense que, ex nihilo, le dessin de presse a un avenir. Enfin, on aurait besoin de lui, mais effectivement la situation n'est guère brillante. D'un point de vue économique on parle d'Internet bien sûr, mais est-ce que quelqu'un ici parmi vous, parmi les dessinateurs, connaît un dessinateur qui vit en publiant des dessins sur Internet? Si la réponse est positive, tant mieux, mais pour ma part je n'en connais pas! Internet est une vitrine, mais ce n'est pas un lieu où l'on peut gagner sa vie, me semble-t-il, ni en France, ni ailleurs.

D'autre part, dans les journaux, les rédacteurs en chef ou les directeurs artistiques, ou les gens qui décident, ont de moins en moins envie de prendre des risques. Donc, quand on ne veut pas prendre de risques, on ne va pas passer le dessin qui risquerait d'offenser des barbus ou telle ou telle communauté.

Ça ne s'appelle pas de la censure parce qu'on fait appel justement aux syndications. Les Américains ont des syndicates, qui sont des regroupements de dessinateurs qui, tous les jours, proposent des dizaines de dessins aux différents journaux qui sont leurs clients. Donc, le décideur, rédac' chef ou directeur artistique, a le choix entre dix, vingt, trente dessins. Quand on a le choix, s'il y en a un qui risque de poser problème, on ne le prend pas! Parce qu'il y en aura forcément un autre qui sera bien aussi, et, tant qu'à faire, autant passer un «bien » qui ne pose pas de problème, plutôt qu'un dessin qui risquerait d'en poser!

En plus, j'ai l'impression qu'en France le dessin de presse est considéré comme un genre mineur. Peut-être qu'on va me contredire, j'aimerais bien, mais... Combien y a-t-il eu d'articles sur l'exposition Saul Steinberg qui s'est tenue récemment à la Fondation Henri Cartier-Bresson? Qui, parmi vous, est allé la voir ? Qui a déjà acheté un dessin de presse, pour le mettre sur son mur, dans des ventes aux enchères ou des choses comme ça ? En France, le dessin de presse reste un " petit dessin ». Il y a quelques années, Sergueï, dessinateur du Monde, me racontait, énervé, qu'il en avait assez qu'on lui demande à chaque fois un "petit dessin " pour mettre avec un article. Et il dit:
Table ronde : Quel avenir pour le dessin de presse? 
"Moi, je ne fais pas de "petits dessins", je fais des dessins de presse. " Effectivement, quand on dit "petit dessin ", c'est plutôt dépréciateur... Ça suppose une petite chose vite faite, sur le coin d'une table et pas bien payée.

En matière d'exposition, je trouve formidable que Beaubourg fasse une exposition sur Gourmelin. Mais à quand les autres ? Où sont les autres ? Où sont les espaces d'exposition en France? Je pense qu'il en manque sacrément ! Les journaux ont leur responsabilité aussi là-dedans. À Londres, par exemple, le Guardian, qui a inauguré de nouveaux locaux il n'y a pas très longtemps - quatre, cinq ans - a créé un espace d'exposition. Dans cet espace, il y a très régulièrement des expositions de leurs dessinateurs maison, qui sont de grands dessinateurs. Prenez Le Monde par exemple, il y a un immense hall d'entrée qui pourrait très bien accueillir des expositions. Mais c'est impossible déjà d'y rentrer car il y a une porte tournante et il faut montrer patte blanche, etc., c'est un lieu vide!

Je voulais vous faire part aussi de quelques remarques des dessinateurs que j'ai interrogés sur leur vision de l'avenir du dessin de presse. Martyn Turner est, pour moi, un grand dessinateur, l'un des deux ou trois dessinateurs qui sont un peu des intellectuels, aussi. Il y a lui, il y a Leff Danzinger, ce sont des dessinateurs dont on sent qu'ils pourraient écrire - pour confirmer ce que disait Charb tout à l'heure. Lui, il dit : «L'avenir du dessin de presse, c'est l'avenir de la presse!» Mais le problème est qu'aujourd'hui la presse a des difficultés partout dans le monde et qu'un des moyens de se différencier, c'est - enfin pour lui, en tout cas dans son journal, selon ce que lui a dit sa rédactrice en chef - d'avoir de bons dessins de presse. Donc, elle l'incite à ne pas partir à la retraite, alors qu'il commence à en avoir largement l'âge. Elle lui a dit : « Si tu pars à la retraite, je te confie une mission, qu'il faut que tu remplisses absolument, c'est de te trouver un successeur ! » Le seul successeur qu'il trouve est quelqu'un qui a deux ans de moins que lui, ce qui est un peu problématique.

J'ai aussi un témoignage assez intéressant de Daryl Cagle. C'est un dessinateur américain relativement jeune, qui a surtout créé un syndicate. Il diffuse tous les jours sur Internet auprès de qui veut. On peut acheter très facilement par Internet toute une flopée de dessins, non seulement des dessins américains, mais également des dessins de dessinateurs européens, asiatiques, etc. Voilà ce qu'il m'a dit : " Je suis en désaccord total avec la plupart des cartoonistes, des dessinateurs qui pensent que l'avenir du dessin de presse est Internet et le dessin animé sur Internet, donc le dessin de presse animé. Eux, ils pensent que c'est l'avenir parce que techniquement, c'est possible, mais moi qui suis à la tête d'une syndication, je dis qu'il n'y a aucun marché pour ça, que personne n'en achètera jamais. En revanche, dit-il, on vend aujourd'hui beaucoup moins de dessins à des grands quotidiens, mais on en vend beaucoup plus, à des tarifs inférieurs évidemment, à des sites Internet, des petits journaux, des journaux spécialisés, des journaux régionaux. Ça, dit-il, ça vaut aux États-Unis. " Donc, il voit un avenir au dessin de presse, mais beaucoup plus morcelé qu'il n'est aujourd'hui.

François Forcadell : J'ai oublié de dire que Faujour allait faire des dessins dans notre dos. Ce serait bien d'expliquer ce que sont les syndicates aux États-Unis, parce qu'en France ça n'existe pas. On a dans la salle

\section{4}

Table ronde : Quel avenir pour le dessin de presse? 
le responsable du site Iconovox qui essaie de fédérer un grand nombre de dessinateurs pour vendre des dessins, mais en France, ce genre de formules est inexistante.

Odile Conseil : Un syndicate est un regroupement de dessinateurs. Les syndicates aux États-Unis peuvent vendre des dessins ou des articles. Nous, à Courrier International par exemple, pour republier les articles, on passe assez souvent par des syndicates. Par exemple, le New York Times a son syndicate, dans lequel il met en vente et les articles du New York Times, et toute une série de dessins qui ont été faits par leurs dessinateurs maison. Mais il y a aussi des syndicates comme celui de Daryl Cagle, ou comme CWS - Cartoons and Writers Syndicate - qui est assez connu. Ils fédèrent des dessinateurs, diffusent leurs dessins et après, ils paient les dessinateurs en fonction des publications. Cette agence de cartoons qu'on a créée à Courrier International et dont je m'occupe cherche à faire la même chose puisque quotidiennement on reçoit des dizaines de dessins. Tous ne sont pas publiés, beaucoup sont bien, beaucoup pourraient trouver à être publiés ici ou là. L'idée est, effectivement, de mettre à disposition de qui veut - éditeurs scolaires, journaux français et étrangers - des dessins. Dans ces cas-là, en général, nous - je crois que les autres syndicates font pareil -, quand un journal nous paie pour la publication d'un dessin, on fait fifty-fifty entre le dessinateur et l'agence.

François Forcadell : En fait, c'est une agence! Donc, il y aurait deux agences en France maintenant: la vôtre et celle d'Iconovox. C'est important à dire, parce que ce métier est très isolé. Des dessinateurs font de l'artisanat, ils travaillent pour eux et vont vendre leurs dessins tous seuls. Enfin, il y a très peu de regroupements de dessinateurs pour des tas de raisons...

Odile Conseil : Mais à Courrier, il n'y a que des dessinateurs étrangers. C'est toujours pareil, c'est le principe de Courrier: articles étrangers, dessinateurs étrangers. C'est vrai que souvent des jeunes dessinateurs français viennent frapper à ma porte et $j$ 'avoue que je ne sais pas très bien quoi leur dire, ni où les envoyer !

François Forcadell : Il faut leur dire d'aller sur Iconovox, qui regroupe des dessinateurs français. Il y a une base de dix-sept mille dessins... On va passer à l'utilisation du dessin en France, notamment à Libération. On peut commencer à parler du dessin à Libé: est-ce qu'il y a une politique éditoriale bien précise? Alain Blaise !

Table ronde : Quel avenir pour le dessin de presse?

Alain Blaise : À Libé, on a beaucoup de chance, parce qu'il y a une culture de l'image au journal, et ce depuis le début. Donc, le terrain est un peu balisé pour nous. Ce n'est pas forcément un espace dévolu au texte sur la page, contrairement à plein d'autres supports. Les gens sont habitués, ils aiment bien avoir un dessin dans leur page, qui va mettre en valeur leur article. Mais j'ai encore une fois beaucoup de chance, parce qu'il n'y a que très peu de titres qui peuvent... Enfin, il y a une espèce de confort de travail. On a toute liberté pour appeler qui on veut, pour tel ou tel sujet. Il y a la Une, les espaces de reportages dessinés, les prépublications d'albums, les illustrations sur tel ou tel sujet. Par exemple : sujet économie, sujet science, sujet « faits 
divers glauques ", etc. Il y a donc plein d'espaces possibles. Donc, à la Une, Willem. Willem fait deux dessins par jour, qu'il nous envoie à midi. Il choisit ses sujets comme il veut. On choisit entre les deux. En général, on a à choisir entre "très bien " et " excellent» ou bien " excellent » et « excellent ». On est un peu ennuyés ! On fait ce choix en fonction soit de l'actu, soit de ce qu'on monte en Une, soit de ce qu'on a passé la veille. Souvent ses dessins défont la Une, tout simplement parce que, sans se concerter et sans un seul coup de fil de la rédaction en chef, dès le matin il a déjà suivi toute l'actualité et devine ce qui va faire la Une de tous les autres, radios, télés, etc. Sur les deux dessins, l'un passe dans la page "Rebonds » classique et l'autre fait la Une. Parfois, il y a une commande de dessin d'illustration pour un sujet donné, dans le cas où la photo est insuffisante ou pas assez forte, quand une photo-concept à faire ou à shooter dans l'après-midi va être trop juste et qu'on n'a pas le temps, etc. Il y a aussi Bertrand Bepdehom, ça c'est un exemple. Contrairement à Willem qui fait ce qu'il veut, et avec lequel je me contente de placer les titres autour, avec Bertrand, je commande : " Il me faudrait ça! " Je lui fais un rough, je lui donne les formats et là-dessus, il me fait deux ou trois esquisses et on choisit...

François Forcadell : Tout à l'heure on parlait de la difficulté à définir le dessin de presse. Là, en l'occurence, ça devient une illustration, c'est du dessin d'illustration utilisé dans la presse.

Alain Blaise : C'est ça! Willem a un statut d'éditorialiste, comme Plantu et les autres de rédacteurs en chef ou de directeurs adjoints à la rédaction, ou ce qu'on veut dans la hiérarchie des écrivants. Il s'exprime plutôt par le dessin, donc il donne son avis. D'autres dessinateurs sont les deux : ils peuvent faire du dessin d'illustration et du dessin éditorial, par exemple Guy Laufer. Souvent, je lui ai demandé plein de trucs pour illustrer des sujets multimédias, etc. Dans La Vie Catholique, il avait sa tribune. D'autres, comme Bertrand, c'est plutôt l'illustration pure et dure. Dans certains cas identiques, les gens sont un peu cadrés, il faut vraiment quelque chose de précis. Donc, c'est moi qui intervient. Dans d'autres cas, ils ont de très bonnes idées tous seuls, je me contente de regarder leurs chefsd'œuvre et je leur dis : " Je prends. » Puis je mets la typo autour. On a aussi un numéro Spécial Angoulême qu'on fait tous les ans, tout en dessins.

Il faut un peu d'organisation et de travail. Il y a trente-quatre, trentecinq commandes, dont quinze que j'étale sur quinze jours à la Une. Par exemple, on a eu Charles Burns. J'ai planché un mois en amont à peu près. Sinon, je commande vingt dessins d'un coup entre une heure et demie et deux heures et demie pour les sujets d'actu. Le reste est préparé un peu à l'avance, la page " Portrait ", la page " Grand angle ", la page « Reportage ", la Une et puis les cahiers. Il y a toujours le cahier «Livres".

Sardon est le deuxième dessinateur éditorialiste qu'on a eu, après Willem, ces dix dernières années. Sa première Une était un peu le fruit du hasard. C'était un pouce, un peu à la Steinberg d'ailleurs. C'était à je ne sais plus à quelle occasion. Depuis, on a fait des sujets un peu plus légers. Puis, de fil en aiguille, au fil des mois et des années, il est devenu un fantastique éditorialiste, à mon avis un des meilleurs dessinateurs- 
éditorialistes de Paris, maintenant. Des fois, c'est moins éditorial, on a plus travaillé, c'est plus « illustration » qu' « éditorial». Il a fait un dessin sur "Internet ", certains parleront de « traitement visuel »... Bref, il a longuement illustré le multimédia avec son traitement hachures-points, son gratté à la Edward Gorey. Il a eu des sujets super drôles, des dessins hilarants sur le multimédia. Rocco, lui, cumule avec l'utilisation d'Illustrator, etc. Moi, parfois, j'utilise Internet, un peu par facilité. Là, c'est pareil, il choisit son idée, il se débrouille et c'est moi qui mets la typo... C'est très joli ! Il y a très peu de travail de contrainte avec ces gens-là, c'est toujours parfait.

François Forcadell : Alors, qui décide que la Une va être dessinée ou non ? Â quel moment ça se décide, cette option?

Alain Blaise : Il y a assez rarement débat, en fait. Elle s'impose d'ellemême. Si c'est la guerre, ou quelque chose dans le genre, c'est évidemment une photo d'actu. Si c'est une élection, en général la veille d'une élection, c'est un dessin de Willem, parce qu'on sait vaguement la tournure que ça va prendre, ou des fois il y a une petite surprise, comme aux municipales, etc. Et le lendemain, c'est plutôt une photo d'actu, de candidats élus, à chaud. La dernière fois c'était exceptionnel, parce que, comme il y a eu plein de villes qui avaient basculé à gauche, on a préféré prendre le dessin de Willem - qui était déjà fait depuis la veille ou l'avant-veille même, puisque c'était un lundi.

François Forcadell : Le dessin était prévu pour l'intérieur ou pour la Une?
Alain Blaise : C'est-à-dire qu'il avait envoyé ça comme il fait d'habitude. Là, c'était la publication du lundi, et comme il ne bosse pas le lundi, le dessin devait être là depuis trois jours. Il y avait les photos d'actu avec les têtes des maires nouvellement élus dans les villes qui passaient à gauche. Mais la Une aurait été composite, un peu compliquée et ennuyeuse, le dessin s'imposait de lui-même. Donc, le directeur de la rédaction l'avait déjà sur son bureau au début de la réunion de Une, avec la manchette la plus rapide que quelqu'un - votre serviteur - ait jamais trouvée. C'est parti tout de suite : trois minutes en tout. D'habitude, il faut plutôt une heure - une heure et demie pour trouver le titre, avec le chef de service, le journaliste, le chef de séquence, le secrétaire de rédaction en chef, l'iconographe, le chef photo, moi, directeur de la rédaction, et il n'en sort pas grandchose. Là, trois minutes : le dessin de Willem, ils le regardent, moi je dis : «Bling! Banco!

\section{7 \\ Table ronde : Quel avenir pour le dessin de presse?}

François Forcadell : C'est l'exemple type d'une Une qui était prévue en photo et qui est passée en dessin pour être plus percutante.

Alain Blaise : Voilà, c'est ça. Alors, le choix d'une photo ou d'un dessin se fait tout de suite ? Bien sûr : qui dit "actu» dit immédiatement "photo "! Et le dessin pour tous les sujets un peu compliqués ou impossibles, le paysage audio-visuel français, les banques, comme on l'a dit tout à l'heure... D'emblée, ça s'impose. $\mathrm{Ou}$ bien, avec le chef photo, on décide de faire une photo "fabriquée ", spécialement en photo-concept. Mais c'est toujours casse-gueule et toujours beaucoup moins percutant qu'un dessin. On ne se pose même pas la question. Donc, si le chef photo voit 
qu'il y a trop de souci et d'ambiguïté, ou de problème de brief à la personne, c'est le dessin tout de suite. Dans le dessin il y a toute la palette, du dessin éditorial au trait, ou au dessin hyperréaliste, comme le fait Bertrand. Le dessinateur qu'on tient par la main, à qui on fait le rough, celui à qui on donne juste le sujet chuchoté au téléphone et qui rend deux ou trois chefs-d'œuvre parmi lesquels on n'a plus qu'à choisir, c'est typiquement le cas de Willem. Ce serait difficile d'imaginer une photo à la place. Pour assurer, Willem est parfait!

Pour parler d'un autre numéro d'Angoulême, ce n'est pas toujours le président du festival qui fait la Une mais bon, de temps en temps... Charles Burns, l'autre fois, ça faisait dix ans que je rêvais de le faire travailler. En fait, on me l'a présenté, il est très simple d'accès. François, lui, ça fait longtemps que j'adorais son boulot. Les dessinateurs doivent mettre la Une en abîme, en faire un objet. Lui, il en a fait une affiche, Charles une télé, Pétillon a fait un journal dans le métro, Mandryka, c'était une bulle avec le Concombre Masqué. Margerin a fait Lucien qui tient le journal, Boucq, une oreille d'éléphant. Bref, il y a toujours le logo dedans, mais on se débrouille pour caser la manchette comme on peut... On avait eu deux dessins un matin, et Laurent Joffrin voulait absolument axer sur le côté... sur la laïcité, quoi ! Qu'est-ce qu'on allait dire de plus ? Et là, le dessin s'est imposé tout de suite. Donc, j'ai pris le dessin prévu pour la page des débats. On a enlevé la pub qui était dedans, et hop! C'était absolument parfait. On a gardé Carla évidemment, parce que ce n'était pas prévu... C'était un petit clin d'œil qui ne méritait pas d'être supprimé.
François Forcadell : Et la bulle, elle est dans le même sens que le titre?

Alain Blaise : Oui, bien sûr. Je ne sais plus ce qu'il y avait dedans. L'avantage avec Willem, c'est qu'il est tellement fort, avec ou sans la bulle, que parfois il y a un jeu. Donc, ça impose de ne pas l'enlever, pour ne pas dénaturer ou détruire le dessin. Parfois, il est tellement balèze qu'il sait, de toute façon, si jamais le dessin est pris en Une, que c'est absolument impossible d'avoir la bulle en plus. Sémantiquement, le message ne passe pas. Il y a la manchette à titrer, je ne saurais même pas où la mettre! Il y a un double effet, ce n'est pas possible. Donc on l'enlève et là, ça marche très bien!

François Forcadell : À combien vous évaluez à Libé l'impact d'une Une dessinée sur les ventes, par rapport aux Unes traditionnelles?

\section{8}

Alain Blaise : Toutes les $\mathrm{x}$ années, des " artistes » du marketing débarquent en disant: "Ça ne se vend pas!» Oui, c'est vrai. Bertrand, encore une fois... Je vais demander une boîte à lettres en forme d'urne funéraire et hop ! terminé ! Oui, le dessin ne fait pas vendre, il n'a jamais fait vendre. C'est triste, mais c'est comme ça, depuis le New Yorker, depuis Courrier International dont j'ai vu refaire la maquette, justement du temps où c'était entièrement dessiné. C'était le seul endroit de France où il y avait des Unes dessinées avec uniquement des bons Gutting, tout ça. C'est triste et, en plus, c'était au moment où j'étais dans le studio de création qui faisait ça. C'était ma copine qui l'avait fait! Le dessin en Une est invendable, ça ne vend pas, sauf au New Yorker. Mais le New Yorker, c'est autre chose. Néanmoins, il faut
Table ronde : Quel avenir pour le dessin de presse? 
mettre des dessins en Une. Voilà, c'est tout. La plupart des sujets qu' on fait, nous à Libération, c'est beaucoup de politique intérieure française. Donc, une fois qu'on a eu Sarko de face, de profil, de dos, en silhouette, tache, contre-plongée, plan américain, plan d'ensemble, avec le nez, la botte, la chaussure, les talonnettes, la main, la nuque... c'est difficile de cibler un sujet extrêmement précis, parfois compliqué, si on n'a pas le dessin. C'est absolument impossible, en fait.

François Forcadell : Oui, c'est déjà beaucoup, tout ce tu viens d'énumérer, pour un seul.

Alain Blaise : Le dessin en Une ne vend pas, ou vend mal, sauf quand le sujet lui-même est tellement porteur que c'est le sujet qui porte! Mais on s'en fout, on continue évidemment, surtout pour la politique intérieure française. Un dessin, c'est un coup de poing dans la gueule qui donne un avis. Donc, on ne peut pas faire " thèse, antithèse, synthèse " comme un discours de Sciences Po ou un éditorial, ou un oral à Polytechnique... La France, c'est le pays du baratin, le pays des encyclopédistes, le pays où la langue règne! Les Anglo-Saxons, là-dessus, ont de l'avance sur nous. Ils n'en sont plus guère au stade de la théorie, ils sont à la fois à la forme, plus forts en typo, en graphisme et en dessin comme vient de le dire ma camarade, mais cela ne veut rien dire pour nous, il faut continuer d'en faire. En plus, maintenant, la communication est mondialisé, n'estce pas? Le dessin est absolument indispensable pour faire passer un message clair. Le problème, c'est que les gens veulent se couvrir, ils ont peur. Donc ils vont dire : «On dit ça, mais on dit aussi son contraire. " $\mathrm{Ce}$ à quoi je réponds : «On ne peut pas faire entrer un rond dans un carré !" Donc, il faut se démerder pour que ça tourne autour du dessin, en rendant le message visuel, global, crédible et intelligible. Et une Une, c'est comme un logo, ça doit être visible sur la surface de l'ongle du pouce, visible sur un panneau d'autoroute à 250 à l'heure, et très vite, "switchée » quoi, manchette, dessin, message... mission accomplie!

François Forcadell : Très bien. Là en plus, ça nous a permis de voir les différents métiers d'illustrateurs et de dessinateurs politiques.

Alain Blaise : Oui, et des illustrateurs, il y en a plein, vraiment une foultitude, mais des dessinateurs politiques éditorialistes, il y en a malheureusement extrêmement peu ! Quand je suis arrivé dans le métier, il y a quinze, vingt ans, les deux plus jeunes s'appelaient Rémi Malingrey et Lefred-Thouron. Là-dessus sont arrivées les nouvelles générations du nouveau Charlie en 1992, Luz, Charb et toute la bande. Ce sont « les Derniers des Mohicans »! Depuis Sardon - je compte Sardon comme étant une aventure personnelle à Libération -, le nombre de merdes que je reçois par mail ou au courrier, de gens qui veulent commenter l'actualité en dessin, c'est hallucinant! Harcelé par fax tous les jours depuis un an, par des mails, des spams, des trucs, je balance ça dans la poubelle avant même d'avoir lu... tous les matins! Il $\mathrm{y}$ en a plein qui veulent le faire et très peu qui réussissent. C'est très étrange ! C'est un métier à part, un métier de journaliste d'abord, et qui s'exprime par le trait, en plus. Mais il faut une culture générale encyclopédique, une documentation pharaonique, il faut un mur entier de tronches de Bush,
Table ronde : Quel avenir pour le dessin de presse? 
de Chirac, de Pompidou, Giscard, René Coty, etc. Il faut tout connaître, tout suivre et en plus, il faut savoir dessiner et être drôle. On vient dans ce métier par hasard... Sardon n'était pas destiné à ça et Willem, il dessinait des bites dans Hara Kiri il y a trente ans, donc, il n'y a pas de lois. Mais c'est vrai que ça manque cruellement. Et je ne vois pas de candidats. Le dernier que j'ai vu, c'était Luz que j'aurais voulu avoir - c'est il y a dix ou quinze ans -, je ne sais plus quand, en 1992 ? Il avait apporté de ces trucs, il avait vingt ans, c'était magnifique, je lui ai dit: "C'est pour Charlie? Mais il n'y a pas encore de Charlie!" C'était quelques mois avant la sortie du nouveau Charlie. Voilà ! Quinze ans! Je ne vois rien, je ne vois pas de candidat!

François Forcadell : Il ne faut pas désespérer, il y a quand même Catherine Meurisse qui a débarqué.

Alain Blaise : J'ai oublié Catherine. Merci d'exister ! Absolument !

François Forcadell : Et elle est passée par l'Ecole Estienne aussi. Peut-être qu'il y a des filières... Elle a une culture graphique, une culture générale, mais bon, c'est un cas parmi...

Alain Blaise : C'est le cas sur des centaines, des milliers, je ne sais pas, des dizaines de... C'est un métier super dur!

François Forcadell : Le problème c'est que pour ce métier, dans la mesure où ce sont des autodidactes, ça demande dix ans, quinze ans d'apprentissage : dix ans de travail avant de pouvoir s'épanouir...
Alain Blaise : Il n'y a rien de plus terrifiant en fait, parce qu'il faut un support. Et pour les centaines de gens qui voudraient faire ça, il y a un titre, deux titres, trois titres. Qui va essayer de prendre le risque de lancer quelqu'un comme éditorialiste ? Ça vient toujours par petits bouts : un dessin par-ci, une Une pas trop mal par là, la direction qui s'habitue, et là, ça commence. Mais il faut la rencontre entre un dessinateur qui a vraiment envie et qui est balèze d'une part, et un support qui soit prêt à le recevoir et à l'accueillir d'autre part, et des gens pas trop peureux derrière. C'est une combinaison chimique qu'il y a une fois tous les...

François Forcadell : On va passer à Bernard Fournier. Moi, ce qui m'a frappé, quand Bernard Fournier a fait son exposition sur Cabu à l'Hôtel de Ville, c'est qu'elle a connu un gros succès public. Ça ne désemplissait pas, il y avait de beaux dessins, il y avait... Toutes générations confondues, il y avait aussi bien des jeunes que des personnes qui connaissaient Cabu depuis les années soixante-dix, alors on peut sans doute se poser la question du support. C'est l'accès au support, peut-être que les supports ne sont pas adaptés aux dessins et les expositions sont aussi... Ou le livre, mais le livre, on peut en parler également.

Bernard Fournier : Je crois que les deux, le livre comme les expositions, sont très difficiles à monter. Je veux dire que là, pour Cabu, la chance exceptionnelle, c'était qu'on était à la Mairie de Paris, rue de Rivoli, dans un espace qui était très lisible. Mais le constat qu'on peut faire c'est que, sur Paris et même en France, on a très peu de lieux consacrés aux dessins, et aux dessins de presse. Pour ce qui
Table ronde : Quel avenir pour le dessin de presse? 
est de l'édition, c'est un peu le même problème, le même souci. Je veux dire que déjà les livres en général se vendent mal, mais alors en plus, les livres de dessins ne se vendent pas du tout ! Donc, ça correspond à quoi ? Est-ce que c'est qu'en fin de compte, le dessin de presse, les gens aiment bien le voir dans leur journal le matin au café, mais ensuite, reformaté, remis en page dans un livre, d'un seul coup il n'a plus la même saveur, il n'a plus le même goût? C'est la question : pourquoi les livres de dessinateurs se vendent-ils mal ? Pourquoi est-ce qu'on ne peut pas monter d'expositions de dessinateurs ? Voilà. Je n'ai pas les réponses...

François Forcadell : Mais quand on conçoit une exposition, on va vers le public, on essaie de présenter des dessins dans un format déjà inhabituel! Souvent le format de l'original est beaucoup plus grand. Donc, peut-être que le dessin prend déjà une autre dimension.

Bernard Fournier : Ça a le mérite de valoriser le travail du dessinateur. C'est-à-dire que d'un seul coup on n'a plus l'interface du papier imprimé, on a son travail à son échelle, avec ses ratures, avec ses fautes, avec ses taches, on est dans la matière brute. C'est un autre éclairage pour les gens qui passent dans l'exposition, de voir le travail du dessinateur. Mais le vrai souci...

Alain Blaise : Je crois que le rôle du dessin de presse c'est d'être publié, diffusé, balancé à la poubelle, c'est exactement ce que je fais tous les jours... Et le côté sacralisé du truc, oui, bien sûr! Pour un dessin qu'on a adoré, pour un dessin emblématique, qui nous touche. Mais la peinture, un tableau, c'est un autre circuit. Un dessin, c'est comme un journal, tu le fous à la poubelle. Est-ce que ça fait rire ou pas ? Est-ce que tu t'en souviens? Si ça devient mémorable, si ça devient un dessin historique, comme ça peut l'être parfois, soit par hasard, soit parce que le vent de l'histoire l'a posé comme ça? Frottons les choses! Willem me dit : "Alain, il y a une exposition Chaval. » Mais Chaval vend vingt mille francs et pour être vendu, il faut être mort ! Il a raison! Là-dessus, je pense à des gens qu’on aurait pu croiser, comme Roland Topor et Willem. Je remercie... je ne sais pas qui a eu l'idée à Beaubourg, de faire une expo. Il faudrait se rendre compte que ce gars-là est un géant du graphisme du $\mathrm{xx}^{\mathrm{e}}$ siècle et qu'il n'est pas immortel, comme les autres, comme Roland Topor.

Bernard Fournier : Mais dans les livres que je fais, ce que je leur propose, ce n'est pas de publier intégralement, d'une façon mécanique, les dessins jour par jour. C'est justement de faire une sélection parmi les dessins qui sont intemporels. C'est la qualité graphique, la qualité de l'idée qui reste. Donc ça demande - du moins c'est ce que je pensais -, j'imaginais que ça pouvait mériter d'exister - en plus du journal - dans un livre. Le constat que je fais, c'est que ce n'est peut-être pas sa place.

Alain Blaise : Je suis d'autant plus d'accord avec toi que je parlais de ventes d'originaux en fait, je ne parlais pas des livres. Il est évidemment indispensable d'accumuler un peu de mémoire dans les bouquins, sinon qui le ferait? Surtout le dessin de presse, qui est justement mal traité par définition. Donc, merci de faire ce boulot. Moi, je ne connais le dessin de presse que par les livres!
Table ronde : Quel avenir pour le dessin de presse? 
Bernard Fournier : Il faut trouver de généreux sponsors pour continuer à financer les livres sur les dessins de presse, parce que sinon, ça n'existera plus. Qu'est-ce qu'on a comme production en ce moment?

François Forcadell : Rien. Mais est-ce que justement, ça ne peut pas nous permettre après de réfléchir à : comment le dessin de presse doit-il s'adapter ou, peut-être même, évoluer dans son contenu? Parce que, si on prend la $\mathrm{BD}$, si on prend l'illustration, on l'a vu là avec les Unes de Libé, les illustrateurs s'adaptent aux nouveaux outils, à un nouveau mode d'expression qui renouvelle un peu le graphisme. Peut-être que le dessin de presse... Pour les dessins à l'étranger, ils reprennent pratiquement les mêmes codes que les dessinateurs français, sauf certains qui sont un peu plus graphiques, par exemple des dessins avec une ombre portée derrière. C'est plus une recherche de graphisme. C'est vrai qu'il y a des moyens d'expressions qui ont su évoluer : l'illustration, la vidéo... Le dessin de presse a toujours gardé ses codes, qui sont peut-être maintenant devenus incompréhensibles pour des générations qui lisent autrement, qui regardent et qui consomment l'image autrement. Enfin, c'est peut-être une question à se poser...

Odile Conseil : Je pense qu'il y a une question d'habitude. Plus on voit de dessins de presse - c'est ce qu'on disait déjà tout à l'heure - plus on les comprend et plus on les aime. J'ai une histoire intéressante à vous raconter. Le Nouvel Observateur m'appelle en disant : "On publie un dessin de notre correspondante en Italie sur la fascisation du régime. " Donc, la correspondante écrit que les dessinateurs italiens représentent tous Berlusconi en mini-duce, on voit beaucoup de dessins sur le sujet. On me demande un dessin italien qui serait paru récemment : j'envoie plusieurs dessins, il y en a un sur Berlusconi où il est question de fascisme et un autre sur le fascisme aussi... enfin il n'y a jamais un dessin, le dessin idéal. Manifestement, le directeur artistique voulait Berlusconi en duce, ce qu'on trouve d'ailleurs chez d'autres dessinateurs. L'Allemand Hachfeld en avait fait un qu'on a publié dans Courrier, mais bon, ça, c'est un regard étranger. Les dessinateurs en Italie, pour comprendre et apprécier leurs dessins, il fallait les voir quotidiennement, il fallait être dans cet univers graphique. Un des dessinateurs du Corriere della Sierra représente constamment Berlusconi. D'abord, si on ne le voit pas tous les jours on ne sait pas que c'est Berlusconi. On a besoin à un moment qu'on vous dise : «Oui, c'est bien Berlusconi. » Il le représente avec une banane, parce quil estime, lui, en tant que citoyen-dessinateur, que c'est une république bananière, donc Berlusconi est toujours affublé d'une banane! C'est pareil, c'est du code visuel, de l'habitude, mais si on l'ignore, même d'un pays à l'autre, on est totalement désorienté par rapport à ça.

François Forcadell : Au Figaro, c'était déjà le cas de Jacques Faizant par exemple, qui avait ses propres codes. Mais justement, moi c'est la question... On va peut-être en parler avec l'École Estienne, moi ce qui me trouble, c'est que le public du dessin de presse ne se renouvelle pas trop. Il y a des jeunes par exemple, qui achètent les nouveaux journaux hebdomadaires, même Charlie Hebdo, mais on n'a pas un renouvellement massif de la clientèle intéressée par le dessin de presse, et je voulais savoir si à Estienne il y a des élèves qui s'intéressent à ça ? 
Luce Mondor : Oui, bien sûr. Je vais vous tenir un discours très optimiste. Déjà j'aimerais tout d'abord réenfoncer le clou de l'idée, puisqu'à l'Ecole Estienne - je pense que vous la connaissez de réputation - tout le monde sait dessiner. Alors pourquoi créer un trophée du dessin de presse quand il y a des fanzines absolument partout ? Justement, c'est pour lutter contre cette suprématie du trait. Ce qui va peut-être vous étonner, c'est que je vous parle de Presse Citron, qui est mon bébé! Ce trophée du dessin de presse a été créé il y a seize ans par quatre profs de lettres. C'était déjà « l'État dans l'État ». Il s'agissait de privilégier le dessin intelligent - et le dessin intelligent qui fait rigoler bien sûr, puisqu'il n'y a pas plus fédérateur, mais ça a déjà été dit et redit. Les objectifs de cette affaire, c'était essentiellement la lecture de la presse, la production de dessins de presse et aussi, surtout, la rencontre entre les étudiants et les dessinateurs professionnels. Puisqu'à la base, il s'agit d'un double concours, à savoir que les dessinateurs professionnels viennent à l'école - ils adorent ça d'ailleurs, revenir sur les bancs de l'école, tout le monde adore ça! Donc, ils votent pour les dessins réalisés par les élèves, pas seulement ceux de notre école, mais ceux des écoles d'arts de la France entière, puisque maintenant le bébé a grandi. Parallèlement à cela, les étudiants votent pour le meilleur dessin d'actu publié. Il faut qu'il ait été publié dans l'année. Alors, très rapidement, les dessinateurs qui sont venus - tous les grands noms, Plantu, Willem, je ne fais pas de liste exhaustive, ça serait vexant - ont été enthousiasmés de rencontrer des jeunes gens et de parler avec eux. Ils nous disaient à l'époque : " Il y a une très grande solitude chez le dessinateur de presse, il est là, chez lui tout seul, il cherche son idée et puis il faut qu'à midi il l'ait envoyé, son dessin. » Â l'époque, c'était par fax, maintenant ça a un petit peu évolué. Donc, en fait, il ne voit jamais personne et en plus, ils ne se rencontrent pas tellement entre eux.

Donc là, c'était une espèce de forum. Ça a tout de suite vachement bien marché ! Quant aux étudiants, de toute façon il suffit qu'on leur propose quelque chose pour qu'ils soient partants. Je ne vous apprendrai rien en disant qu'ils sont tous pleins d'idées. Ça, c'était ce qui préludait à cette création. Vous allez me dire : « Pourquoi un concours? " Oui, ça ne fait pas très dessin de presse, l'idée de concours! Vous comprendrez bien que le concours en fait, est un prétexte. Il y a des gens qui ne l'ont toujours pas avalé ! Je parle du Canard Enchaîné. Les dessinateurs du Canard Enchaîné sont interdits de participation par la rédaction. On arrive quand même à les choper parce que, quand il s'agit de venir discrètement participer au vote, c'est-à-dire voir les copains, boire un coup, rencontrer toutes ces jolies filles, et voir tous ces beaux dessins, là, ils viennent ! Mais ils viennent presque incognito! Cet aspect "concours" nous a un peu plombés. Le revers de la médaille, c'est que ça nous a permis de faire connaître des jeunes, et des jeunes formidables. Nos premiers gagnants par exemple, Fred Benaglia, David Poulard, pour ne citer qu'eux, sont tous devenus directeurs artistiques maintenant. Je ne reparlerai pas de Catherine, mais Catherine était élève à l'École Estienne. Elle a été lancée, si je puis dire, par le Presse Citron. Évidemment, son talent a fait le reste et sa culture aussi, puisque Catherine est avant tout une littéraire. Elle avait fait auparavant des études de lettres et d'ailleurs, elle vient de publier - petit 
copinage, au passage, si elle en avait besoin - un livre formidable qui s'appelle Mes hommes de lettres ${ }^{22}$.

En essayant d'être rapide, un petit mot sur : comment on initie au dessin de presse, comment on initie les jeunes gens, et comment on entretient cette fièvre. Car il s'agit vraiment de fièvre créatrice. D'abord, on leur fait lire la presse. Vous savez bien que les jeunes n'achètent pas la presse, mais ils la lisent! Là, nous bénéficions - j'en profite parce qu'il y a des représentants de la presse parmi nous - nous recevons - beaucoup d'écoles sont d'ailleurs dans ce cas - gratuitement, chaque jour, une centaine de journaux. On a Libération, on a Le Figaro, bien sûr. Mais ce n'est pas toujours mauvais, même du point de vue du dessin de presse. On a La Croix souvent, bref, on reçoit des journaux. L'Équipe? Non, jamais. Les étudiants les lisent. C'est une première chose. Ensuite, on leur donne des cours. Quand je dis " on ", c'est d'abord les profs, parce qu'ils savent un petit peu faire! On fait des brainstormings, on choisit un sujet. Il y a cette fièvre créatrice qui se met en place. Mais on fait surtout appel aux intervenants extérieurs, c'est-à-dire aux dessinateurs professionnels qui viennent volontiers, qui animent des ateliers et ça, c'est formidable! Ça prend tout de suite une autre envergure! On organise également des expositions. Lorsque Charlie Hebdo avait treize dessinateurs avant l'événement que vous savez, ça tombait bien, c'était le treizième épisode du Presse Citron. Donc, on a organisé une Expo Trez. Avec, en même temps, treize dessinateurs. On a eu Vial... On change chaque année. Cette année nous aurons Desclozeaux. Donc, vous voyez, le spectre est assez éclectique.

Voilà, en gros, notre démarche péda- gogique. Je voudrais, pour terminer dire un petit mot sur l'avenir, puisque c'est pour cela que nous sommes tous ici. Me semble-t-il, un certain virage se produit dans la production elle-même, dans le fond et dans le style. Les deux dessins d'étudiants gagnants de l'année dernière, par exemple, ça n'avait rien à voir avec la caricature. Je crois que les étudiants, comme vous tous, comme nous tous adultes, en ont eu un peu marre de l'omniprésence de Sarkozy. C'est vrai qu'il est très facile à faire. Chaque étudiant en graphisme un peu doué fait un carré, deux, trois "zigouigouis » à côté et il tient son Sarkozy ! Mais ça, il y en avait marre. Donc, l'ensemble de la production, les 400 dessins - c'est déjà une présélection - qui ont été en concours présentaient des choses beaucoup plus poétiques, beaucoup moins axées sur l'actualité et des dessins plus proches du rêve, finalement. Catherine Beaunez - qui est dessinatrice, je crois - regrettait que le mot rêve ne soit pas ajouté aux «3 $R$ » du dessin de presse. J'irai dans votre sens et je crois qu'actuellement, au niveau de la jeunesse, en tout cas, on va beaucoup vers le rêve.

François Forcadell : Si je peux ajouter quelque chose, c'est vrai que c'est une tendance que j'ai remarquée sur les blogs - beaucoup de dessinateurs ont des blogs, maintenant. Je navigue pas mal pour essayer de voir les évolutions graphiques, les nouvelles signatures et notamment chez les femmes. Il y a beaucoup de femmes qui dessinent et qui, effectivement, ne vont pas directement vers le dessin politique, elles font du dessin de société. Elles parlent d'elles, elles parlent de leurs problèmes, c'est vrai qu'il y a une forte tendance... Ce sont des dessins à mi-chemin entre la bande dessinée et le dessin poli-

\section{4}

Table ronde : Quel avenir pour le dessin de presse? 
tique. Il y a une nouvelle sensibilité. Même des dessinateurs qui font de la BD, comme Jean-Yves Ferry ou Diego Aranega, traitent de sujets qui sont à la lisière de l'actualité : des sujets de société, mais avec un regard différent, avec moins de virulence, moins de cynisme que ne le font les dessinateurs de presse, les caricaturistes.

Bernard Fournier : Est-ce que le dessin de presse doit être forcément politique? Le dessin de société, ça peut être un dessin de presse, aussi.

François Forcadell : On en revient toujours à la définition du métier.

Luce Mondor : Si je peux me permettre, même s'il est effectivement très difficile d'être dessinateur professionnel, tant que le dessin de presse reste un plaisir et qu'il peut circuler sur les blogs et dans l'affichage sauvage, dans les tracts - c'est vrai qu'on retrouve un peu la vocation du dessin de presse du $\mathrm{XIX}^{\mathrm{e}}$ siècle - il est vivant, c'est déjà ça! Tant pis pour les nouilles! Ce n'est pas mauvais, là non plus!

François Forcadell : Ce qui m'intéresse, c'est l'évolution de ce métier, de voir les jeunes déjà, le regard qu'ils portent sur le dessin de presse existant. Est-ce qu'ils apprécient ? Est-ce qu'ils arrivent à lire, par exemple, les dessins de Cabu ou de Willem ? Pourquoi n'y a-t-il pas plus de dessinateurs qui prennent cette pente, ce chemin-là ?

Bernard Fournier : Je crois que la BD a beaucoup entraîné, elle a vampirisé un peu le talent d'expression des dessinateurs. C'est plus facile, je veux dire que ça consiste unique- ment à bonifier un talent de dessin, pas uniquement à rajouter du sens. Depuis vingt ans, effectivement, le statut des dessinateurs de $\mathrm{BD}$ a enflé et attire beaucoup de jeunes talents. Mais d'un seul coup, on réalise et on voit, quand Alain fait son numéro sur Angoulême, sur les trente dessins qui sont publiés, je ne parle pas des histoires de $\mathrm{BD}$, souvent c'est une belle illustration mais il n'y a pas d'idées.

Alain Blaise : Parfois, certains trouvent de très bonnes idées. Ils pourraient verser facilement dans le dessin.

Bernard Fournier : Il y a très peu d'exemples de dessinateurs de BD qui sont passés aux dessins de qualité.

Alain Blaise : Non, non, c'est un autre exercice.

Bernard Fournier : C'est un autre exercice, une autre discipline, une autre contrainte, un autre regard.

Alain Blaise : Mais quand je vais pour les diplômes de fin d'études dans toutes les écoles d'arts graphiques de Paris, en fait, il y en a très peu qui s'intéressent au print - sans parler du dessin ou de l'illustration ! Il y en a les trois quarts qui font du multimédia et, franchement, le papier pour eux c'est du vieux! Je me suis retrouvé dans les jurys de dessin des jeunes étudiants en deuxième ou troisième année d'école et il y avait ce paradoxe que certains avaient envie de faire des dessins politiques, mais ne lisaient pas un seul journal. Sur les trente que j'ai eus en face de moi, il y en avait un qui avait lu L'Équipe le matin, je crois. Les vingt-neuf autres n'avaient jamais rien lu ni même ouvert depuis une semaine ou deux
Table ronde : Quel avenir pour le dessin de presse? 
en presse quotidienne. Donc, je crois que tout le monde est à fond sur le multimédia et les derniers dinosaures du print...

François Forcadell : Tout à l'heure, Guillaume Doizy parlait des Guignols de Canal +, c'est vrai que ça fait beaucoup de tort aux dessins de presse d'opinion. C'est-à-dire aux gens qui s'expriment et ont des idées, et qui veulent les transmettre.

Odile Conseil : JIl y a une chose révélatrice, c'est que parmi les trois quotidiens gratuits qu'on trouve à Paris, aucun d'eux n'a de dessin éditorial ! Il y a un dessin quotidiennement dans Matin Plus, fourni par Courrier International, mais c'est un dessin qui accompagne un article, ça ne mange pas de pain ! C'est souvent joli, parfois drôle, parfois légèrement grinçant, mais on n'est pas dans le dessin éditorial, parce que ça poserait des problèmes!

Alain Blaise : C'est la bonne remarque, parce que, effectivement, dans les gratuits, il n'y a pas de prise de position. Le seul dessin qu'il y a, c'est une petite BD, un strip.

François Forcadell : De toute façon, on ne peut pas faire un constat totalement négatif, quand même! Sinon, on va boucler la journée!

Odile Conseil : Non, je pense que, par rapport à ce que disait Daryl Cagle, l'Américain de la syndication, c'est sans doute vrai aussi en France, on peut espérer qu'il y ait des tas d'espaces, mais de petits espaces. Ça veut dire, pour les dessinateurs, une visibilité moindre. Éventuellement, une notoriété moindre aussi, puisqu'il y a quelques stars en France - on le voit bien dans les salons ou dans les conférences, il y a une espèce de masse qui vient se mettre autour du dessinateur, parce que c'est à lui qu'on veut parler, que c'est lui qui semble le plus accessible, le plus sympathique. C'est lui qu'on va tutoyer, c'est ce que disait Charb, tout à l'heure. Il faut sans doute trouver des espaces. Je pense que dans la presse spécialisée, il y a du dessin qui n'est pas politique. Mais ça peut être du dessin qui dit quelque chose.

François Forcadell : Déjà, satirique, ça serait bien.

Odile Conseil : Ça existe mais on le sait moins, parce que c'est moins visible.

François Forcadell : Moi, j'ai toujours constaté que même à travers - et c'est ce que je voulais dire tout à l'heure - une exposition comme Cabu et Paris -, il y a vraiment un décalage par rapport à l'attente du public qui va vers les dessins. De toute façon, même un journal comme Charlie Hebdo peut arriver à vendre 500000 exemplaires de son journal. Je ne dis pas qu'ils le font chaque semaine, mais il y a quand même un public qui aime ça. D'autres journaux ont très peu de dessins, ou même pas du tout. Vraiment, il y a un grand écart entre l'attente des lecteurs et la volonté des journaux qui n'ouvrent pas leurs colonnes, qui ne font pas venir les dessinateurs. Ils pourraient former. Par exemple, les dessinateurs du Monde, Chenez et Plantu, quand ils ont démarré, ils étaient très mauvais comme dessinateurs. Mais Le Monde avait une politique de recrutement, de formation des dessinateurs. Ils ont attendu cing ans, dix ans. Il y a très peu de journaux qui font ça maintenant. 
Odile Conseil : C'est fini, ça! Dans les journaux, on ne forme plus non plus les jeunes journalistes, alors qu'avant on les formait. Maintenant, ils sont formés essentiellement dans les écoles !

François Forcadell : Ne nous lançons pas sur le sujet des journalistes!

Luce Mondor : Oui, mais au-delà de la formation, il faut quand même être très courageux pour être dessinateur de presse, parce qu'il faut être en état de veille permanente. Et ça, pour un artiste, je pense qu'à un moment donné... Surtout qu'en plus l'artiste, il est un peu narcissique, donc il a envie d'être reconnu pour ce qu'il est, etc. Donc là, c'est vraiment le lancer sur un terrain mouvant. Il gagnera beaucoup plus de fric et il sera beaucoup plus à l'aise, intellectuellement, comme directeur artistique ! Il fera de la communication, il vendra de la soupe. Mais, vraiment, cette veille et cette colère permanente qui lui sont nécessaires, s'il veut faire du dessin de presse, c'est vraiment très dur! Moi, je suis extrêmement admirative pour ceux qui les ont et qui continuent à les vivre.

François Forcadell : Oui, il y en a encore quelques-uns. Mais je pense que c'est comme pour tout métier artistique, quelqu'un qui veut être comédien et qui veut arriver en haut de l'affiche... C'est une appréciation personnelle!

Luce Mondor : En plus, ça va encore plus loin, parce que c'est un comédien qui fait du direct tous les jours! Et comment dormir? Il se trouve que j'en connais quelques-uns personnellement, ça les empêche de dormir ! En même temps, ils en rêvent tous! Toute une vie en éveil!
François Forcadell : Ça fait partie du métier. C'est un métier de création. Donc, la création, on ne sait pas où on va la chercher. L'imagination, ça fait partie du métier. Ce n'est pas plus dur que d'aller travailler à l'usine huit heures par jour et de gagner le SMIC.

Luce Mondor : C'est vachement angoissant parce qu'il faut fournir! Là, il y a quand même le couperet, tous les jours, à telle heure ! C'est vrai qu'après, il y a une certaine habitude. Mais ce n'est pas une vie facile.

François Forcadell : Personne n'est obligé de le faire non plus. Mais c'est valable pour tous les créateurs. Si vous discutez avec ceux qui écrivaient les textes des Guignols, eux aussi, ils vous diront: "On n'y arrive pas, on n'a plus d'idées, ça, on l'a déjà fait... " C'est vrai aussi qu'ils ne sont pas aidés par la vie politique. Le dessin politique est le reflet de la vie politique. Comme ça ne se renouvelle pas beaucoup, qu'il n'y a pas beaucoup d'idées... Mais en même temps, ça fait partie du métier de créateurs.

Odile Conseil : Il y a aussi ce que j'appelle le dessin compassionnel, qui peut être très beau, mais ne cherche pas à faire rire. C'est là qu'on voit la différence entre des dessinateurs. Quand il se passe un événement comme le 11 septembre ou dans le genre, il y a d'abord un effet de sidération pendant un, deux, trois jours. On voit ce genre de dessin prendre une vraie distance par rapport à l'humour, comme s'il y avait un temps à respecter avant de pouvoir essayer de faire rire - autant qu'on puisse faire rire avec ce genre de sujet, mais il y en a qui y arrivent toujours.
Table ronde : Quel avenir pour le dessin de presse? 
Bernard Fournier : C'est pratiquement du dessin-symbole.

Odile Conseil : Il y en a de beaux !

François Forcadell : Ou efficaces. De toute façon, même dans l'Histoire, on remarquera que le dessin a toujours existé pendant les périodes de révolte, des périodes où l'on avait vraiment des choses à dire. Guillaume Doizy a cité les guerres de religion. C'est vrai qu'il y a eu une bagarre entre les différentes parties. Après, il y a eu la Révolution française, puis la Commune. Chaque fois, même sous Louis XIV, il y avait des caricatures. Chaque fois, quand il y avait des idées ou une révolte à exprimer, même en mai 68, il y a eu des dessins. Ça a produit L'Enragé, par exemple, qui a été un creuset où on trouvait Cabu, Pétillon, tous ceux qu'on retrouve maintenant, d'ailleurs. C'est vrai que depuis quelque temps on n'a plus ce souffle de révolte, ni dans l'actualité ni chez les dessinateurs. Cabu, il a eu treize procès contre l'armée parce qu'il était vraiment anti-militariste !

Bernard Fournier : Peut-être aussi que le débat dans la société n'existe pas!

François Forcadell : Oui, c'est ce qu'on disait tout à l'heure, il n'y a plus de débat.

Bernard Fournier : Les journaux se sont concentrés. Il y en a même de moins en moins. Pourquoi, d'un seul coup, spontanément, une nouvelle génération de dessinateurs apparaitrait-elle? Il faut qu'il y ait un appel d'air!

François Forcadell : C'est juste une façon de réfléchir à ce qui va se passer. Ce que je disais tout à l'heure, c'est qu'il faut dix à quinze ans pour faire un dessinateur. Si on se projette de maintenant à dans quinze ans, pour l'instant - à moins qu'il y ait des générations spontanées - ça ne se profile pas. Ça aussi, c'est comme quand on est comédien, il faut un peu crever de faim. Quand on discute avec l'équipe de Charlie Hebdo du début, ils avaient tous envie de se battre, ils avaient tous envie d'exister.

Alain Blaise : Je peux me permettre une remarque ? Il y a le politiquement correct qui est passé par là, parce que tu imagines, "Bal à Colombey, un mort "... Maintenant, le problème pour le dessinateur est le même que pour tous les humoristes. Coluche aujourd'hui sur scène, Reiser dans les pages, tu imagines? C'est le procès immédiat! Ils seraient en taule, maintenant, direct!

François Forcadell : Oui, mais Charlie Hebdo est un journal créé par des créateurs, enfin des dessinateurs, des auteurs qui avaient envie de dire quelque chose. L'Enragé, ça a été pareil. Ce sont des gens qui ont envie de s'exprimer. Peut-être que l'avenir du dessin de presse est dans la multiplication des titres créés par les auteurs, les dessinateurs. Mais quand on voit la difficulté de créer un journal aujourd'hui, c'est vraiment lourd ! Et comme Internet - Odile le disait tout à l'heure - ça ne rapporte rien aux dessinateurs... Pour l'instant, on ne gagne pas sa vie en publiant ses dessins sur Internet.

Alain Blaise : Mais par contre, on peut être connu. Ça, c'est bien. Il y a un jeune dessinateur qui est venu me voir, je ne sais pas pourquoi, je lui ai parlé de Politis, peut-être... Je lui dis : «Essaie Politis! » Politis veut le prendre sur son site, pas payé, évipour le dessin de presse? 
demment. Puis, au fil des semaines, il a versé d'Internet au papier. Ça c'est un truc. Lautre truc, c'est l'histoire de Thierry Guitare. On bossait souvent ensemble, il y a dix, quinze ans, avec le multimédia, tout ça. Maintenant, il fait toujours ses bouquins sur le rock. Thierry me dit : "Alain, j’ai été contacté par le New Yorker, car là-bas Chris Curry était sur Internet. " Je lui demande : « Pas d'autres réseaux ? - Non! » Il a juste double-cliqué et hop ! il a trouvé. Donc, Internet pour ça, c'est fantastique.

François Forcadell : Internet est l'outil pour se faire connaître. Par exemple avant, les dessinateurs avaient des books pour démarcher les journaux. Ils rassemblaient une trentaine de leurs dessins pour montrer ce qu'ils savaient faire. Ils démarchaient les directeurs artistiques. Maintenant, c'est vrai, ils ont Internet. Mais ce n'est pas parce qu'on est sur Internet que tout le monde nous voit, non plus.

Alain Blaise : Non, ça aide, c'est tout.

François Forcadell : Ça aide, mais il faut se faire connaître. La démarche de rencontrer les gens, d'aller vers eux, vers des directeurs artistiques, des journaux ou des agences, il faut quand même la faire, même si on va sur Internet. Internet, ce n'est pas la solution. Du moins pour l'instant. Moi, je crois plus à la télé, mais le problème, c'est qu'il faut que ça s'ouvre. Il faut que la liberté d'expression soit plus large pour le dessin, parce que le dessin à la télé, ça a toujours plu. À Droit de réponse, ils avaient une revue de presse au début, qui marchait très bien. Elle s'est arrêtée le jour où il y a eu un dessin contre TF1. Mais la télé est un bon support qui permet, en plus, de rémunérer les auteurs. Peut-être qu'il faudra monter des émissions de télé avec du dessin. Sur des chaînes câblées, on peut faire des choses, un peu comme les séries américaines.

Alain Blaise : Au New Yorker il y a trois avocats, pour être sûr que le restaurant est bien représenté, qu'il y a bien le nombre de fenêtres, etc. Je dis ça sans le contrôle de Chris Curry!

François Forcadell : Ça rejoint ce qu'on disait. On va voir avec le nouvel hebdomadaire qui est sorti... Mais à Charlie, ils n'avaient qu'une limite - Siné l'a dit -, c'était l'avocat. C'est-à-dire que dès qu'un dessin était susceptible de tomber sous le coup de la loi, il ne le publiaient pas. Donc, si un journal satirique fait ça, je ne vois pas où est l'avenir du dessin de presse...

Rousseau : J'ai remarqué une chose, toutes les entreprises qui ont été mises en place pour promouvoir le dessin de presse à partir de " un bon dessin vaut mieux qu'un long discours" - ça a été suivi ensuite par Gros Nez magasine, Une Minute de silence et autre chose fait par Dobritz - toutes ces entreprises avaient un dénominateur commun, la fourniture gratuite de dessins de presse. Je crois que le dessin de presse, c'est la seule chose qu'on puisse demander gratuitement sans avoir honte, à l'heure actuelle. C'est vrai qu'un dessinateur est appelé à fournir des dessins dans son existence, une somme incalculable de gratuité !

François Forcadell : Toutes les associations ne livraient pas du dessin. Pour reprendre un bon dessin, c'étaient des expositions, le festival de 
la caricature d'Épinal, qui était une vitrine tous les ans pour les dessinateurs. Il y avait cent dessinateurs qui venaient à Épinal. C'était une vraie vitrine pour ce métier. Ce n'était pas gratuit. Les dessins étaient déjà publiés dans les journaux.

Rousseau : Alors, ils devenaient gratuits, de ce fait. Ça, je le sais, c'est l'argument classique.

François Forcadell : Ils ne les donnaient pas gratuitement, puisque personne ne les achetait ! Ce n'était pas une vente, c'était une exposition.

Rousseau : Enfin, pour les autres il y a eu beaucoup de choses après. Il y a aussi sur Internet les Gueules d'humour et compagnie.

François Forcadell : Mais ça dépend des dessinateurs.

Rousseau : C'est toujours gratuit.

François Forcadell : Je prends deux exemples. Un dessinateur qui accepte de faire des couvertures de livres, de casser les prix, va travailler, mais alors, il fera baisser le prix pour tout le monde. Il y a d'autres dessinateurs qui refusent de baisser les prix, qui disent : "Voilà, mon travail, je l'estime à tant. Je ne travaillerai qu'avec les gens qui me le paieront tant. "À ce moment-là, il y a des gens qui vivent très bien parce qu'ils ont refusé de baisser les prix. C'est comme un petit artisan, comme un plombier qui casse les prix.

Rousseau : Juste un petit détail à propos des récents événements qui se sont produits concernant le licenciement du dessinateur Siné. Je ne pense pas du tout qu'il soit antisémite! Là, il y a une erreur de jugement. Simplement, je crois qu'il s'est trompé d'époque, parce que s'il avait fait la même chose en 1940, tout le monde aurait été content! Il n'y aurait eu aucun problème!

François Forcadell : Ce n'est pas sûr. Pour évoquer ce sujet, on a décidé de ne pas en parler, parce qu'il s'agit de textes. C'est une affaire entre deux personnes, entre Val et Siné. On a pensé que ce n'était pas utile d'en parler, dans la mesure où ça n'intéressait pas le dessin de presse et, encore moins, son avenir. C'est un conflit entre deux personnes. Chacun porte le jugement qu'il veut là-dessus. Il y a les pro-Siné... Mais en même temps, ça n'a pas fait avancer le schmilblick de tout l'été Le dessin de presse n'y a rien gagné du tout! Bien au contraire, je pense qu'il recule, comme avec les histoires des caricatures de ...

Luce Mondor : $\mathrm{Si}$, le dessin de presse a quand même gagné un hebdo en plus!

François Forcadell : Oui, il gagné un hebdo, tant mieux! Mais on va attendre un peu avant de se prononcer. Les caricatures de Mahomet non plus, n'ont pas fait avancer le schmilblick sur le dessin de presse, parce qu'on crée des polémiques sur des choses qui n'ont rien à voir avec le dessin de presse. Pour les caricatures de Mahomet, une manipulation a eu lieu à partir de dessins, de photos et de dossiers qui ont été montés pour $\mathrm{x}$ raisons !... On parle d'autre chose, qui fait partie du dessin de presse. C'est vrai qu'il n'y a pas de dessins de presse dans les pays où il n'y a pas de démocratie, donc il n'y a pas de caricatures.

Odile Conseil : $\mathrm{Si}$, il y a des dessins de presse. Par exemple à Cuba les dessinateurs critiquent Bush, mais c'est facile ! Ou alors, on biaise. Le dessi- 
nateur Ares avait fait par exemple une page de BD. Les deux cases du haut, c'est un monsieur qui dit : «Alors, de quoi on va parler aujourd'hui ? On va parler de la liberté d'expression! ! et toutes les cases suivantes sont blanches! J'ai l'impression - c'est mon interprétation - que le dessinateur qui fait ça à Cuba se dit : « Je sais que je ne peux pas le dire, mais je dis que je ne peux pas le dire, donc je suis quand même vachement libre. " Il y a une espèce de jeu qui doit se faire comme ça. J'ai trouvé ce dessin assez sympathique.

François Forcadell : Il flirte avec la censure! C'est pareil pour Dilem, dessinateur algérien, qui utilise souvent des tas de techniques pour parler de quelqu'un dont il n'a pas le droit de parler. Résultat : il a quelques procès. Mais c'est vrai que dans tous les pays où il y a la censure, où il n'y a pas de liberté, il y a forcément des dessinateurs, ce n'est pas possible qu'ils disparaissent comme ça!

Odile Conseil : Surtout, la créativité est énorme, parce que du coup, on en parle sans en parler, enfin, on en parle autrement! En Russie et avant, en U. R. S. S. , il existait toute une tradition du dessin où on ne représentait jamais aucun homme politique. Mais il y avait tout le temps quelqu'un avec une couronne, et on savait très bien qui était ce quelqu'un avec une couronne...

Bernard Fournier : Il y avait une règle du jeu avec des codes.

François Forcadell : Et ils continuent!

Public: Tout à l'heure vous avez dit, monsieur Blaise, que le dessin de presse était fait pour finir plutôt à la poubelle ? En gros, qu'on lisait un journal et qu'on le jetait...

Alain Blaise : C'est juste une caricature!

Public: J'ai bien compris! Mais qu'est-ce que vous pensez par exemple du cas du dessinateur Steinberg, qui a fait une sorte de glissement du dessin de presse, finalement vers des dessins qui sont aujourd'hui vus dans les galeries ? C'est un cas assez singulier!

Alain Blaise : Saul Steinberg n'est pas un dessinateur de presse, c'est un artiste protéiforme, quelqu'un de spécial pour le $\mathrm{xx}^{\mathrm{e}}$ siècle. Steinberg a inspiré non seulement tous les dessinateurs...

Public: Qu'est-ce que vous entendez par dessinateur de presse ? Il a publié dans la presse?

\section{1}

Alain Blaise : Bien entendu ! Il a fai des reportages.

Public: C'est quoi exactement pour vous alors, un dessinateur de presse?

Alain Blaise : Je disais que le principe même du dessin n'est pas d'être accroché aux cimaises, c'est tout! Moin par exemplen j'ai découvert ça quand j'étais ado, uniquement par les compilations de dessins que j'achetais dans des packs scellés : on les pilonnait, parce que personne n'en achetait. C'est par là qu'on apprend à découvrir doucement le dessin de presse. Ce sont des compilations faites par des gens de bonne volonté, par les éditeurs qui prennent des risques, parce qu'ils savent que ce ne sera jamais vendu. C'est grâce à ça qu'on peut se créer sa propre contre-culture 
de dessins de presse. Donc ça n'a pas une vocation à être jeté évidemment, c'était une plaisanterie! Sa vocation c'est d'être un message, comme un coup de poing dans la gueule, aussi vite oublié qu'une parole, et qui n'est pas destiné à être inscrit dans le marbre! Mais bien entendu, je me régale des compilations. Je félicite des éditeurs courageux et intelligents, par exemple le jeune éditeur des Arènes qui a fait une compilation gigantesque des dessins du New Yorker. Parce que je me souviens, quand j'étais ado, $\mathrm{j}$ 'ai eu une fois l'occasion d'aller aux États-Unis fouiller les bookstores pour trouver des compilations... A part deux, trois vieilles choses de 1925-1945, 1945-1975, il n'y avait absolument rien ! C'était impossible de les récupérer. Donc, quand on est courageux, quand on est éditeur de cette façon, je salue ! C'est magnifique, une belle opération! Je ne sais pas si ça a marché, mais je crois que oui.

Le dessin de presse n'est pas assez diffusé, c'est vrai. Grâce à des opérations comme ça, on connaît un peu mieux Saul Steinberg, qui était un géant multicarte total, qui a inspiré des générations entières de graphistes, mais pas que des dessinateurs, en plus! Enfin, c'est un cas de figure à part, peu ont fait école comme lui ! Je crois que l'exposition des dessins du New Yorker, juste après-guerre, a influencé toute la génération Cabu, Siné, etc. C'est de là qu'est né le dessin de presse français et, ensuite, les nouveaux dessinateurs sont venus de cette deuxième génération, donc Saul Steinberg est à l'origine de tout ça. Je ne veux pas remonter aux grottes de Lascaux pour expliquer d'où viennent les sources de chacun, mais c'est évident que là, c'est un maelström de création venu des États-Unis qui est absolument incom- parable, qu'on ne peut pas attribuer à un seul dessinateur de presse. De la même manière qu'un jour on dira que Willem était un fantastique graphiste, parce que sa gestion des surfaces, des codes visuels, des noirs et blancs, affichée dans l'ultime limite, permet d'exploser tous les codes du dessin dit de presse avec personnages en pied, scènes de théâtre, bulles et en plus légendes, pour ceux qui n'auraient pas compris.

Bernard Fournier : Je crois que le dessin de presse, c'est un peu trop générique. On a le dessin de presse d'actualité, on a le dessin de presse d'illustration, on a le dessin de presse d'humour. La palette est assez large et puis, tous ne sont pas des artistes.

François Forcadell : Exactement, c'est ce qui définit le dessinateur qui travaille dans la presse, il peut être à $50 \%$ artiste, à $50 \%$ journaliste. Pour certains, la part d'artiste va jusqu'à $70 \%$ - ce sont des gens comme Willem - et il reste $30 \%$, enfin, les deux sont mêlés. D’autres privilégient plutôt le journalisme, l'idée, le dessin simple et efficace, mais c'est vrai que les dessinateurs sont toujours partagés entre l'artistique et le journalisme.

Alain Blaise : Je vais me permettre une autre remarque à propos de la narration. La technique de dessin elle-même n'a pas tellement d'importance. De très bons dessinateurs de presse sont parfois de mauvais dessinateurs. Sur ce sujet, c'est assez drôle de voir que justement, Saul Steinberg, par la simplicité totale de son trait, a fait école et certains ont cru qu'en faisant pauvre ils allaient faire simple, et en fait, non! Mais si jamais ils avaient eu des choses à dire, ce n'était pas très important. Par exemple, Jacques Rouxel dessine mal et il le dit. Il aime beaucoup Saul 
Steinberg, il le dit aussi. Il fait des petits dessins animés de trois minutes qui sont des chefs-d'œuvre absolus de drôlerie, peut-être un peu mal dessinés, mais ce n'est pas très grave ! L'essentiel, c'est plutôt ce qu'on a à dire et que les propos ne soient pas vampirisés par une supertechnique. Les gens qui dessinent, quand ils traversent le vent de l'histoire comme Marjane Satrapi dans Persepolis, n'ont pas besoin de très bien savoir dessiner. Je suis désolé de te dire que si ce n'est pas très bien, qu'est-ce qu'on en a à foutre ? L'essentiel est que tu racontes bien ton histoire, ce que tu fais très bien. Art Spiegelman, c'est pareil, il a une culture du collage, une fantastique culture encyclopédique du graphisme qui lui permet, par des pirouettes, de faire de magnifiques Unes au New Yorker. Ce n'est pas forcément non plus un virtuose, ce n'est pas très grave. L'essentiel c'est ce qu'on a à dire et même si on ne sait pas dessiner, on peut quand même se lancer.

Public: Par exemple, si on prend le cas de Daumier, c'était un dessinateur de presse. Il avait une production énorme et, en même temps, il doublait ses dessins de presse par des gravures d'édito qu'il vendait à côté des journaux. On pourrait imaginer ça aujourd'hui.

François Forcadell : Il était peintre, sculpteur et graveur aussi.

Public: Oui, à la fin de sa vie. Ce que j'essaie de mettre en avant, c'est le glissement qu'il peut y avoir. Par exemple, Willem expose aussi. Mais il peut y avoir, pour un dessinateur de presse, d'autres occasions : il peut sortir du journal et exposer ses travaux.

Alain Balise : Il n'y a aucune loi. Ils font ce qu'ils veulent.
Public : Oui, ce sont des artistes, ils font ce qu'ils veulent...

François Forcadell : Il y en a beaucoup qui le font.

Public : Il y en a beaucoup ? Il n'y en a pas beaucoup, justement, malheureusement!

François Forcadell : Si on prend quelqu'un comme Desclozeaux, qui fait du dessin de presse dans $L e$ Monde, il fait aussi de la création artistique quand c'est pour une couverture de livre, ou pour une affiche.

Public : Oui, c'est très bien qu'il le fasse.

François Forcadell : Il y en a beaucoup! Même Soulas, un dessinateur de Libé, quand il est arrivé à la retraite, il s'est mis à faire de la peinture et à exprimer sa part artistique, beaucoup plus que dans la partie dessin de presse liée à l'actualité.

On va poser une question à chacun de nos interlocuteurs, pour une solution à trouver pour l'avenir du dessin de presse, une solution chacun.

Odile Conseil : Moi, j'ai une idée. Je trouve que la presse régionale devrait - et je suis prête à le faire pour elle, avec mon agence de dessins - publier chaque fin de semaine la semaine en six dessins, avec cinq, six, sept dessins sur l'actualité mondiale, hexagonale, avec trois, quatre, cinq lignes de commentaire. $\mathrm{Ce}$ serait un très bon truc de pédagogie parce que malgré tout, les mômes, les ados, verraient le journal de leurs parents. Ils regarderaient, puis on leur dirait : "Tiens, lis-le, tu apprendras au moins trois trucs sur 
ce qui se passe. "Donc, ça serait à la fois ludique et pédagogique et je pense que ce serait bien le travail de la presse régionale de faire ça.

François Forcadell : On va demander à Faujour. Excuse-moi de te réveiller ! Une solution pour que le dessin de presse ait un avenir?

Loïc Faujour : Je ne sais pas. L'avenir ? La chose qui m'emballe le plus, c'est de dessiner en direct, soit dans les débats, soit à la télé, ça me plaît beaucoup. Enfin, il faut dire aussi que je me cogne beaucoup de presse militante! Donc ce n'est pas très intéressant, c'est très limité ! La marge de manœuvre, elle est toute petite! Le dessin en direct, ça me plaît, il n'y a pas trop de souffrance, c'est bien! Des fois, c'est tout raté, des fois c'est un vrai bonheur! Alors, pareil ! De la place à la télé, il n’y en a pas beaucoup ! Il y a plein de chaînes câblées, mais elles ne font pas appel aux dessinateurs. On ne compte pas beaucoup!

François Forcadell : Alain Blaise? Une idée pour l'avenir du dessin de presse?

Alain Blaise : Ça se fera de soi-même, je pense. C'est l'époque qui porte ses propres modes d'interprétation et de contestation, ça s'appellera de soimême dès que ce sera nécessaire, quel que soit le support : électronique, papier ou encore autre chose.

François Forcadell : Sélection naturelle. Luce?

Luce Mondor : Eh ! bien ! ce n'est pas une idée, c'est une recette. C'est que chacun - d'ailleurs vous pouvez le faire, vous tous, là - ait toujours sur soi un petit carnet, un crayon, on devrait déjà les avoir! Et tous les jours, on se force à faire un petit dessin d'actu! Alors, même quand on ne sait pas dessiner, vous verrez que ça vient très vite!

François Forcadell : Bernard Fournier?

Bernard Fournier : Je n'ai pas d'idée. L'œuf ou la poule, je ne sais pas qui est arrivé le premier.

François Forcadell : Écoutez, ce que je propose c'est qu'on se retrouve l'année prochaine, à peu près à la même époque.

Public: Je me permettrais d'intervenir. Je n'ai pas de réponse pour l'avenir du dessin de presse, mais je travaille pour une association qui s'appelle "Paris Bibliothèque ", qui produit avec la bibliothèque Forney et un conservateur d'arts graphiques une exposition autour du dessin de presse international à la fin de l'année. Ça devrait s'appelait Permis de croquer. C'est autour de la liberté d'expression, avec notamment des artistes dont vous avez parlé : Dilem, Willem, $\mathrm{Wiaz}^{23}$, Kichka, des gens comme ça, qui devraient exposer à la fin de l'année, à la Bibliothèque historique de la Ville de Paris, avec des débats, des conférences et éventuellement, un catalogue d'expositions. Je vous dis ceci en avant-première, puisque rien n'est encore validé au niveau de la Ville de Paris, la bibliothèque étant un établissement de la Ville. C'est un projet qui est quasiment bouclé, qui attend des validations au niveau des directions des Affaires culturelles et des Relations internationales. On serait ravis de vous voir tous là-bas.

François Forcadell : De toute façon, des expositions il y en a toujours. En 
ce moment à Saint-Just-le-Martel il y a un festival qui existe depuis vingtneuf ans maintenant, qui rassemble beaucoup de dessinateurs. Il y a beaucoup d'initiatives pour populariser le dessin de presse, on espère qu'elles le feront vivre.

Alain Blaise : Ce sont des initiatives individuelles.

François Forcadell : Voilà. Très bien, je vous donne peut-être rendez-vous l'année prochaine au même endroit. Merci beaucoup. 


\section{Notes}

* Grognet, Thierry : directeur de la Bibliothèque publique d'information.

* ForCadell, François : journaliste et écrivain.

* Dorzy, Guillaume : professeur associé au Centre de recherche en arts de l'université de Picardie Jules Verne.

* Charb : dessinateur et journaliste, rédacteur en chef adjoint de Charlie Hebdo.

* Blaise, Alain : directeur artistique de Libération.

* Conseil, Odile : rédactrice en chef adjointe de Courrier International.

* Fournier, Bernard : commissaire de l'exposition « Cabu et Paris », ancien directeur artistique de l'Équipe Magazine.

* Mondor, Luce : professeur à l'École Estienne et organisatrice du prix Presse Citron.

1. Auteur de : Le Guide du dessin de presse - Histoire de la caricature politique française, Paris, Syros, 1998.

2. Auteur de : Salvat Etchart, un passant considérable, Paris, L'Harmattan, 2002.

3. L'Art et l'histoire de la caricature, de Baridon, Laurent et Guedron, Martial, Paris, Citadelles \& Mazenod, 2006.

4. Peintres et dessinateurs de l'école de Bologne (xve siècle) - Dessin « Feuille de caricatures ».

5. Bibliothèque de documentation internationale contemporaine.

6. Lucas Cranach le Vieux (1472-1553), peintre, graveur et dessinateur (dessins).

7. L'Antijuifillustré : journal cité dans "L'Affaire Dreyfus et la presse ».

8. John GRAND-CARTERET (1850-1827), écrivain et journaliste, auteur de nombreux ouvrages sur l'histoire des mœurs par la caricature.

9. "Célébrités du Juste Milieu » : formule empruntée par dérision à un discours du roi LouisPhilippe se référant à une maxime d'Aristote, in medio stat virtus, par la presse de l'époque. Daumier en fit trois bustes-charges en argile peinte.

10. La Charge: Alfred Le Petit y a publié "La Rose impériale».

11. Charles-Amédée de NoÉ, dit Cham.

12. Exposition virtuelle réalisée par le Centre de recherche en histoire du XIX ${ }^{e}$ siècle.

13. cf. p. $11:$ La Charge

14. Auteur du fameux "Chat noir".

15. Le Tambour et Le Tam-Tam : journaux fondés par Alfred Le Petit.

16. Chauny, ville de l'illustrateur Lucien Émery.

17. Le Rire : nombreuses illustrations de Toulouse-Lautrec

18. Juan Gris (1887-1927).

19. Frantisek Kupka (1871-1957).

20. Maximilien Luce (1858-1941).

21. Conférence du 29 avril 2009.

22. Mes hommes de lettres : Petit précis de littérature française, de Meurisse, Catherine, et Cavanna, Paris, Sarbacane, 2008.

23. Ses dessins dans le Nouvel Obs. 